\title{
The European lonosonde Service: nowcasting and forecasting ionospheric conditions over Europe for the ESA Space Situational Awareness services
}

\author{
Anna Belehaki ${ }^{1, *}$, Ioanna Tsagouri ${ }^{1}$, Ivan Kutiev ${ }^{1,2}$, Pencho Marinov ${ }^{2}$, Bruno Zolesi ${ }^{3}$, Marco Pietrella ${ }^{3}$, \\ Kostas Themelis ${ }^{1}$, Panagiotis Elias ${ }^{1}$, and Kostas Tziotziou ${ }^{1}$ \\ 1 Institute of Astronomy, Astrophysics, Space Applications and Remote Sensing, National Observatory of Athens, \\ Metaxa and Vas. Pavlou 15236, Greece \\ 2 Bulgarian Academy of Sciences, "Acad. G. Bonchev" str., 1113 Sofia, Bulgaria \\ 3 Upper Atmosphere Physics Dept., Istituto Nazionale di Geofisica e Vulcanologia, Via di Vigna Murata 605, 00143 Rome, Italy \\ ${ }^{*}$ Corresponding author: belehaki@noa.gr
}

Received 22 October 2014 / Accepted 7 July 2015

\begin{abstract}
The Earth's ionosphere is a magnetoionic medium imbedded in a background neutral atmosphere, exhibiting very interesting refractive properties, including anisotropy, dispersion, and dissipation. As such, it poses a challenge for several radio systems that make use of signal transmission through all or some portion of the medium. It is important therefore to develop prediction systems able to inform the operators of such systems about the current state of the ionosphere, about the expected effects of forthcoming space weather disturbances and about support long-term planning of operations and data post-processing projects for improving modelling and mitigation techniques.

The European Space Agency (ESA) in the framework of the Space Situational Awareness (SSA) Programme has supported the development of the European Ionosonde Service (EIS) that releases a set of products to characterise the bottomside and topside ionosphere over Europe. The Service is based on a set of prediction models driven by data from ground-based ionosondes and supportive data from satellites and spacecraft. The service monitors the foF2 and the electron density profile up to the height of the Global Navigation Satellite System (GNSS) at European middle and high latitudes and provides estimates for forthcoming disturbances mainly triggered by geo-effective Coronal Mass Ejections (CMEs). The model's performance has been validated and based on these results, it was possible to issue together with the products, quality metrics characterizing the product's reliability. The EIS products meet the requirements of various SSA service domains, especially the transionospheric radio link and the spacecraft operations. Currently, the service is freely available to all interested users, and access is possible upon registration.
\end{abstract}

\section{Introduction}

Space weather is the physical and phenomenological state of natural space environments. The associated discipline aims, through observation, monitoring, analysis and modelling, at understanding and predicting the state of the Sun, the interplanetary and planetary environments, and the solar and non-solar driven perturbations that affect them; and at forecasting and nowcasting the possible impacts on biological and technological systems (Lilensten \& Belehaki 2009).

The mission of the European Ionosonde Service (EIS) is to monitor and predict space weather effects on the ionosphere above Europe, in order to issue nowcasts, forecasts and alerts to potential users of systems whose operation is dependent on ionospheric conditions. In some cases, such as the radio communication and broadcasting systems, the ionosphere is an essential part of the system; in other cases, such as the transionospheric radio communication and navigation systems, the ionosphere is fundamentally a nuisance. In both instances, an account of the ionosphere is at least beneficial to system design and operation (Goodman 2005).

During the last decade there have been a number of initiatives in Europe dealing with the role of space weather in the ionosphere and the near-Earth space environment. Systematic collaboration among the European nations has been supported by the European Cooperation in Science and Technology (COST) through the funding of five Actions, COST 238 (Bradley 1995), COST 251 (Hanbaba \& Zolesi 2000), COST 271 (Zolesi \& Cander 2006), COST 296 (Bourdillon et al. 2010), COST 724 (Lilensten \& Belehaki 2009) and COST ES0803 (Belehaki et al. 2009b, 2014). The first three Actions 238, 251 and 271 developed methods to assimilate various data types (ionosonde derived parameters and Total Electron Content, TEC) for producing instantaneous maps over regions where observing platforms are sufficiently dense and in parallel they studied the problem of worldwide maps by piecing together local "maps". To make the individual maps consistent with each other in the intervening regions where there is little data upon which to develop a data-driven model, a transitional region that merges with climatology after a certain distance has been specified. The effort in developing operational services to characterize ionospheric conditions over Europe started in the COST Action 271 and continued in the Action 296 where, in addition, several mitigation techniques have been designed. In parallel and in an effort to systematize the production and release of ionospheric specification services, based on models developed through these COST Actions, several institutes who operate Digisondes have started a collaborative project funded 
by the EU-eContent Programme to establish the European Digital Upper Atmosphere Server (DIAS). The system was first released in 2006 (http://dias.space.noa.gr) and since then it has been operated by the National Observatory of Athens (Belehaki et al. 2005, 2006a, 2007). The service is based on the on-line processing of data streaming in real time from eight European Digisondes (Athens, Rome, Ebre, Arenosillo, Chilton, Juliusruh, Pruhonice, Moscow). In its first release, the majority of the DIAS services targeted the needs of HF communication users (nowcasting and forecasting of the bottomside ionospheric critical parameter).

As the dependence of the Global Positioning System (GPS) reliability on ionospheric disturbances has been modelled and quantified during the last decade (Hernandez-Pajares et al. 2011), a significant effort has been made by the ionospheric community to support the GNSS community through the development of high precision models able to provide, with the required accuracy, the electron density (ED) profile from the bottomside ionosphere up to the height of GNSS orbits, and its integral which is known as the Total Electron Content (TEC). This effort meets a number of complications. A major difficulty is due to the absence of direct observations of the electron density profile along the full path from the bottomside ionosphere to the plasmasphere. The current observing facilities are ionosondes providing estimates of the electron density up to hmF2 (Reinisch \& Galkin 2011), Incoherent Scatter Radars (ISR) that cover the part of the profile up to $700 \mathrm{~km}$ (Lilensten et al. 2005; Rietveld et al. 2005), and satellite observations from which the Radio Occultation (RO) technique can be used to reconstruct the full electron density profile (Jakowski et al. 2004). New imaging techniques applied to data from ultraviolet imagers provide an additional tool for measuring ionospheric electron density (Comberiate \& Paxton 2010).

The capacity of ionosondes to provide systematically measurements that can be exploited for monitoring purposes is widely acknowledged by the research community, given also the latest improvements in the autoscaling software and the new tools for quality control of the extracted parameters (Galkin et al. 2008, 2013). At the same time, RINEX files from GNSS satellites to ground-based receivers have been widely used for the development of TEC maps (Jakowski et al. 2011; Bergeot et al. 2014) and for a 4D tomographic imaging to map the ionospheric electron density (Allain \& Mitchell 2009). The RO technique, which makes use of radio signals transmitted by the GPS satellites, has emerged as a powerful and relatively inexpensive approach for sounding the global atmosphere with high precision, accuracy, and vertical resolution, as has been proven from the evaluation of the COSMIC/ FORMOSAT-3 mission results (Yue et al. 2012). However for space weather operations, there are still some quality control issues that need to be addressed before the exploitation of these measurements becomes possible for operational applications (Alexander et al. 2014; Mikhailov et al. 2014).

In parallel to these advances in the observational domain, the scientific community has developed models that are able to estimate the full ED profile. These are of two basic categories: assimilation models (EDAM, the Electron Density Assimilative Model, is a representative model, Angling \& Jackson-Booth 2011) and empirical models such as NeQuick (Radicella \& Nava 2010) and TaD (Kutiev et al. 2012). Important developments implemented in the course of the two space weather COST Actions 724 and ES0803 demonstrated the potential of exploiting Digisonde and GNSS-TEC measurements in order to reliably reconstruct the electron density at the topside ionosphere and the plasmasphere and hence, to release a new set of products tuned to the needs of satellite designers and operators who need to know parts of TEC depending on the requirements of each specific application. The establishment of the ESA Space Situational Awareness Programme (ESA SSA) was the ideal framework to further develop and test operationally these services and adjust them as much as possible to the needs of the users.

\subsection{The ESA Space Situational Awareness Programme}

ESA's Space Situational Awareness (SSA) Programme was launched in 2009 and the mandate extended until 2019. The objective of the SSA programme is to support Europe's independent utilisation of, and access to, space through the provision of timely and accurate information and data regarding the space environment, and particularly regarding hazards to infrastructure in orbit and on the ground. The programme is active in three main areas (http://www.esa.int/Our_Activities/ Operations/Space_Situational_Awareness)

1. Survey and tracking of objects in Earth orbit: comprising active and inactive satellites, discarded launch stages and fragmentation debris that orbit Earth;

2. Monitoring space weather: comprising particles and radiation coming from the Sun that can affect communications, navigation systems and other networks in space and on the ground;

3. Watching for Near Earth Objects (NEOs): comprising natural objects that can potentially impact Earth and cause damage, and assessing their impact risk and potential mitigation measures.

To undertake these activities, the programme is federating existing assets and capabilities from ESA, European and international partners into a set of unified SSA capabilities. These are being extended by newly developed infrastructure including databases, software tools and applications and optical survey telescopes and may include dedicated satellite missions in the future.

The Space Weather Segment (SWE) services are organised around several Expert Groups, that provide their expertise, services or applications in five topics, Solar Weather, Ionospheric Weather, Geomagnetic Conditions, Space Radiation and Heliospheric Weather. In Phase I the service topology has been established, according to which, the provision of the user services is federated rather than established in a single location. Thematic service coordination takes place through Expert Service Centres (ESCs) and the overall coordination and monitoring of the day-to-day work is the responsibility of the SWE Service Coordination Centre (SSCC). The SSCC also provides the first level user support for all SWE services. In parallel during Phase I a systematic survey has been completed to list the SWE customer requirements. The SWE Segment customer requirements are related to the monitoring of the Sun, the solar wind, the radiation belts, the magnetosphere, the ionosphere, the thermosphere and the microparticle environment. This document is the starting point for SSA-SWE engineering activities and accordingly segment specifications will have to satisfy these customer requirements and the segment will have to be qualified against them. 

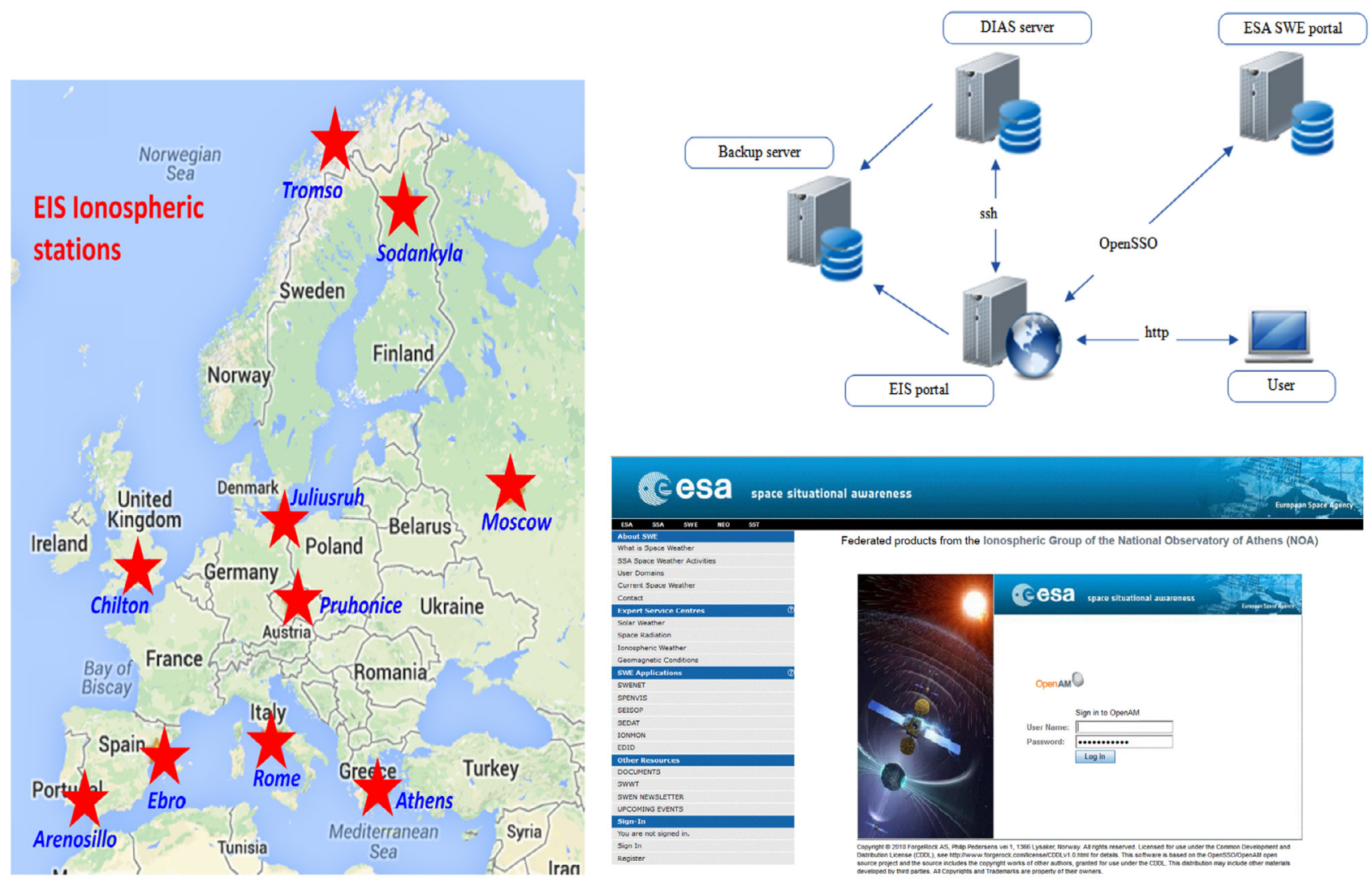

Fig. 1. To the left, the European Ionosondes contributing to the EIS service with real-time data. To the right, the architecture of the EIS service (top) and the EIS login page (bottom).

During its Phase II the SWE segment will pursue the required development activities in close coordination with European and international partners, with primary objective to be fulfilled as follow-on from Phase I, the networking and integration of existing European infrastructure through the creation of a series of Expert Service Centres (ESCs). Additional objectives are the establishment of a new ESC for Heliospheric Space Weather, the implementation of the first hosted payload missions, the procurement of instruments having an identified flight opportunity, the Proba- 2 mission exploitation and the support of studies for an enhanced space weather monitoring system including sensors orbiting at various Lagrange points.

\subsection{The European Ionosonde Service}

The European Ionosonde Service (EIS) following the ESA requirements is based mainly on the exploitation of measurements from ionosondes to deliver the following nowcasting and forecasting services:

- Long-term prediction maps of foF2 over the whole European region based on a combination of the Simplified Ionospheric Regional Model (SIRM) and the Comité Consultatif International pour la Radio (CCIR) model.

- Nowcasting regional maps showing the variation of the foF2 critical frequency over the whole European Region.

- Maps of the forecasted foF2 parameter over Europe for the next $24 \mathrm{~h}$.

- Near real-time TEC maps for the European region.

- Alerts for the forthcoming ionospheric disturbances in the European sector.
- Maps of current ionospheric conditions at each station location.

- Forecasted foF2 values for the next 24 hours over each station.

To develop these services it was necessary to implement a number of models able to run in real-time and provide an updated specification of ionospheric conditions at least hourly. These models are implemented in the DIAS backend, using data from the European ionosondes (Fig. 1, left side), using as additional datasets TEC parameters from the Regional Reference Frame Sub-Commission for Europe (EUREF), and supportive datasets from the National Oceanic and Atmospheric Administration (NOAA) such as solar wind parameters from the Advanced Composition Explorer (ACE) satellite, solar (R12 and f10.7) and geomagnetic indices (predicted $\mathrm{Kp}$ ). The topology of the EIS network is shown at the top-right corner of Figure 1. The EIS portal communicates with the ESA SWE portal using the single sign-on (SSO) protocol. The EIS portal provides the Graphical User Interface (GUI) where all products are available in real-time. Historical values are also kept and provided to the user through the archive interface. Access is given for free from ESA upon registration. The login page of the EIS portal is shown at the bottom-right corner of Figure 1.

The objective of this paper is to present the service, the models on which the EIS products are based, their performance and the quality indicators provided to the users. This is addressed in Section 2. This section is followed by an analysis of the overall increase of the ESA SSA SWE provision capacity that has been achieved with the integration of the 

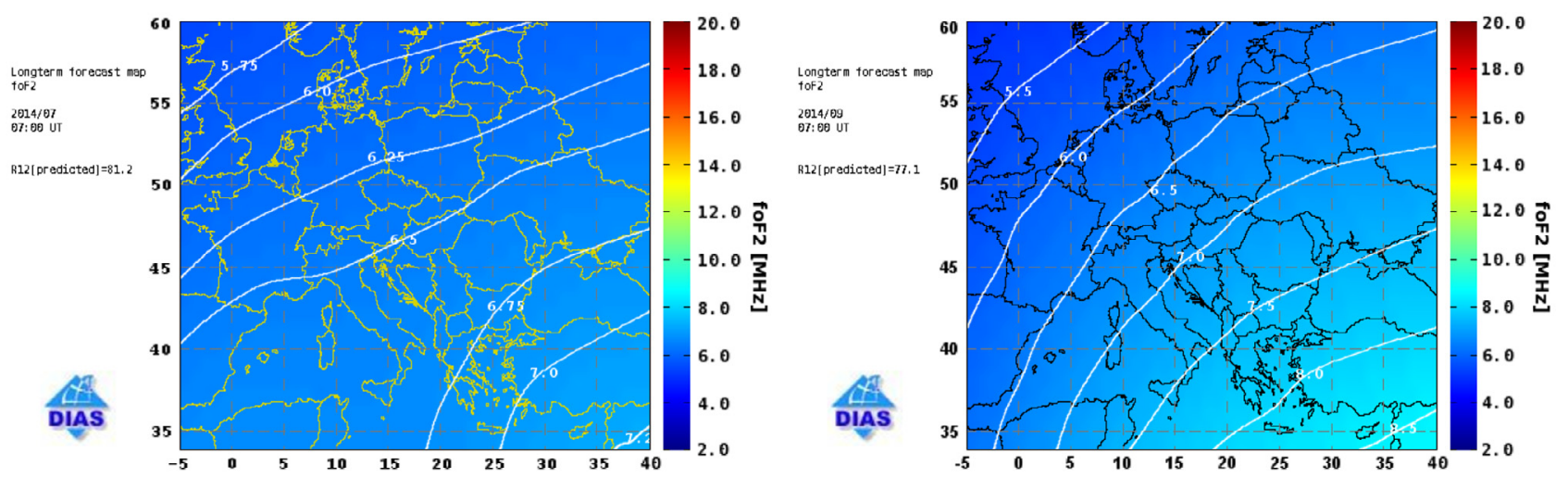

Fig. 2. An example of long-term prediction maps for middle European latitudes released by the DIAS service.

EIS products in the SWE portal. The paper concludes with discussion on further work planned to be done in the near future for improving the service.

\section{The EIS prediction models}

\subsection{The enhanced version of the Simplified Ionospheric Regional Model}

The Simplified Ionospheric Regional Model (SIRM) is a longterm prediction model that provides the key ionospheric characteristics, such as foF2, M(3000)F2, h'F, foF1, and foE, valid within limited areas (Zolesi et al. 1993). It is based on a Fourier analysis of the monthly median values of these characteristics from a number of ionospheric stations operating for several years in Europe. This modelling involves fitting Fourier functions to a reference historical ionospheric dataset assuming:

1. a linear variation of the given characteristics with the 12-monthly smoothed sunspot number R12, as applied in the improved version developed in the COST Action 251 (Hanbaba \& Zolesi 2000),

2. a linear variation of the model coefficients with the geographical latitude within the limited area of Europe,

3. no longitudinal changes at constant local time, and

4. the use of a limited number of Fourier coefficients in the model description that are sufficient for portraying the main features of the mid-latitude ionosphere under median conditions.

The SIRM modelling procedure is the linear regression analysis of the monthly median values of a given ionospheric characteristic taken at local or universal time against the solar index R12. For every different month there are 12 pairs of Fourier coefficients with a linear dependence on the solar activity and on the geographic latitude. A software routine for a Fourier Synthesis is applied at every geographical point spaced $1^{\circ}$ in latitude and $1^{\circ}$ in longitude over the European region to generate the numerical grid of the ionospheric characteristics. The model yields considerable economy in data storage and computation of the characteristics for a given position, instant of time, and solar activity as compared with global and/or other regional ionospheric models (Zolesi et al. 1993).
During the COST 238 (Prediction and Retrospective Ionospheric modelling over Europe) and COST251 (Improved Quality of Service in Ionospheric Telecommunication Systems Planning and Operation) Actions, a testing procedure was developed and applied by an impartial testing team to verify and rank the performances of the different methods including the global models recommended by CCIR now known as the International Telecommunication Union (ITU-R) (Zolesi \& Cander 2008). It was shown that the agreement between the SIRM predicted values and observed data of foF2 and $\mathrm{M}(3000) \mathrm{F} 2$ is best within the European area defined as between $34^{\circ} \mathrm{N}$ and $60^{\circ} \mathrm{N}$ and $5^{\circ} \mathrm{W}$ and $40^{\circ} \mathrm{E}$. The validity of the model could be extended in longitude but not to more northerly latitudes due to the complex ionospheric behaviour in that region. The model has been applied in DIAS since 2006 to provide in real-time long-term prediction of the foF2 and $\mathrm{M}(3000) \mathrm{F} 2$ characteristics over Europe within the above specified area up to 3 months ahead. Representative DIAS maps are given in Figure 2, where predictions released on June 2014 are shown for July 2014 (1 month ahead) and September 2014 (3 months ahead) for 07:00 UT.

To be compliant with ESA SSA requirements, SIRM and CCIR models have been suitably designed to calculate longterm prediction maps for foF 2 critical frequency with a latitudinal extension up to $80^{\circ} \mathrm{N}$. To this effect, CCIR coefficients for the foF 2 are used to map the ionospheric conditions in the high latitude region from $60^{\circ}$ to $80^{\circ} \mathrm{N}$.

The CCIR maps are based on monthly median values obtained by the worldwide network of ionosondes. Each station dataset is first represented by a Fourier time series (in UT), and then a worldwide development in a special form of Legendre functions (in geodetic latitude, longitude and modified dip latitude) is applied for each Fourier coefficient. Coefficient sets are provided for high and low solar activity. For intermediate levels of solar activity, linear interpolation is suggested.

For the collaboration of the two distinct modelling approaches in the development of maps that cover the whole European region up to high latitudes, special consideration was given also to the buffer zone between the global CCIR and regional SIRM models in an attempt to avoid large gradients especially at high latitudes where the behaviour of the ionosphere is complex (Zolesi \& Cander 1998, 2008).

For the implementation of the enhanced SIRM model (SIRM\&CCIR) in EIS, a collective procedure was designed in 

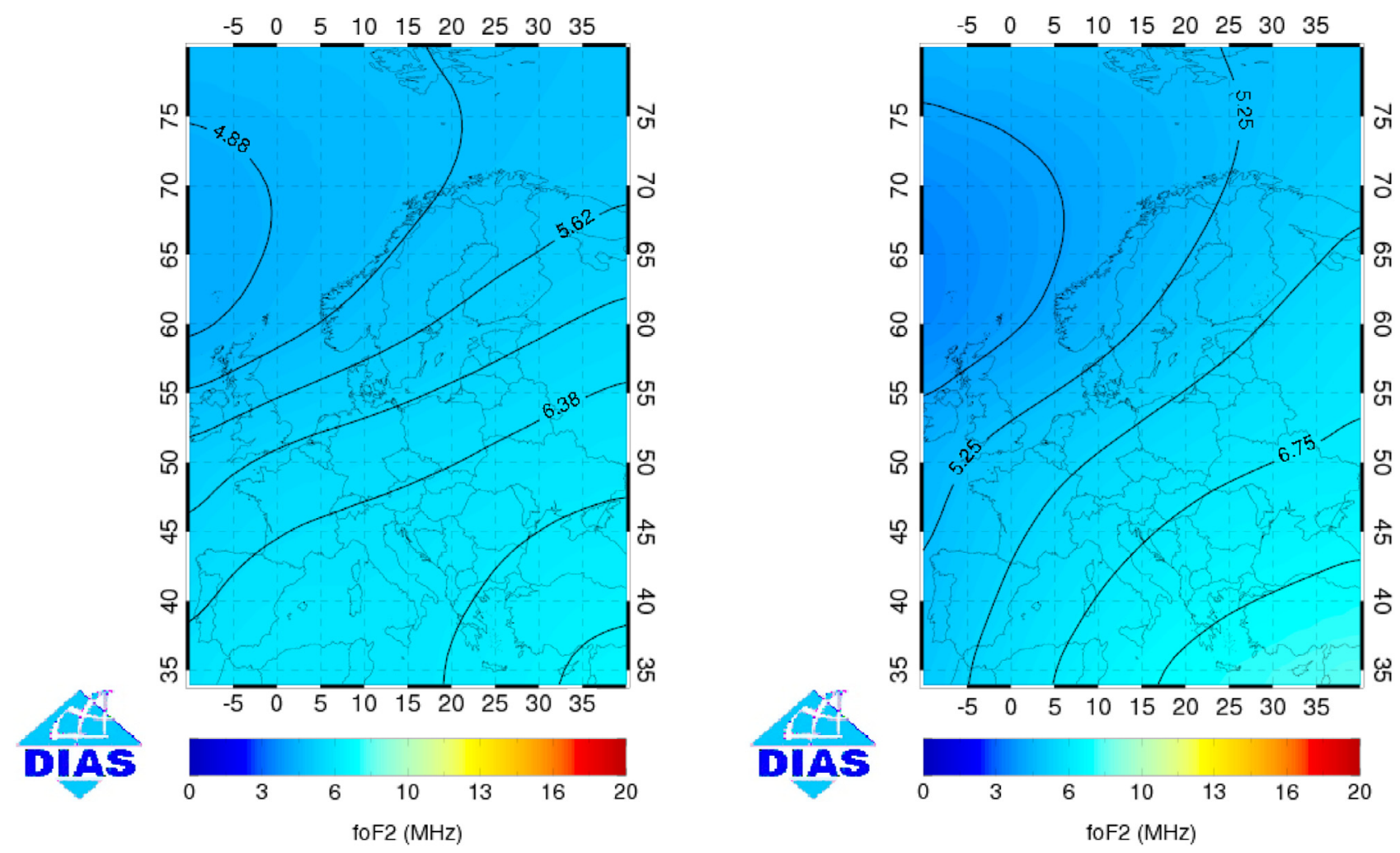

Fig. 3. The EIS long-term prediction map at 0700 UT for July 2014 (1 month ahead prediction, on the left) and September 2014 ( 3 months ahead prediction, on the right).

order to get numerical grids of long-term monthly predicted values, for all the $24 \mathrm{~h}$, in the extended area in latitude from $34^{\circ}$ to $80^{\circ} \mathrm{N}$ and in longitude from $-10^{\circ} \mathrm{W}$ to $40^{\circ} \mathrm{E}$ with a $1^{\circ} \times 1^{\circ}$ degree resolution. The input parameters include the month and the predicted R12 value that is stored in the DIAS database.

The procedure is executed in four logical steps:

1. SIRM_grid: This part uses the codes running in DIAS producing the monthly predictions. It reads the solar activity index R12 and the month under consideration providing the predicted values of foF 2 for all the $24 \mathrm{~h}$ by the SIRM model in the area extending in latitude from $34^{\circ}$ to $60^{\circ} \mathrm{N}$ and in longitude from $-10^{\circ} \mathrm{W}$ to $40^{\circ} \mathrm{E}$ with a $1^{\circ} \times 1^{\circ}$ degree resolution.

2. CCIR_grid: Based on the same input as before, the predicted values of foF 2 for all the $24 \mathrm{~h}$ by the CCIR model are provided for the whole grid ranging in latitude from $34^{\circ}$ to $80^{\circ} \mathrm{N}$ and in longitude from $-10^{\circ} \mathrm{W}$ to $40^{\circ} \mathrm{E}$ with a $1^{\circ} \times 1^{\circ}$ degree resolution.

3. Buffer_zone_grid: this part of the algorithm reads the predicted values of foF2 by the SIRM and the CCIR models, respectively, and calculates in the range of latitude $50^{\circ}-60^{\circ} \mathrm{N}$ (buffer zone) new values of foF 2 by means of a linear interpolation technique.

4. UN_SIRM_BUFF_CCIR: it combines the output of the three previous steps to provide the prediction values of foF2 from SIRM model (in latitude interval $34^{\circ}-$ $49^{\circ} \mathrm{N}$ ), buffer zone (in latitude interval $50^{\circ}-60^{\circ} \mathrm{N}$ ), and CCIR model (in latitude interval $61^{\circ}-80^{\circ} \mathrm{N}$ ).

An example of the long-term prediction map released by the EIS service is given in Figure 3.
To test the performance of the enhanced SIRM, foF2 monthly median (MM) estimates obtained from real-time autoscaled observations were systematically compared with SIRM\&CCIR predictions over three indicative European stations, one in each latitudinal zone: Tromso $\left(69.6^{\circ} \mathrm{N}\right.$, $\left.19.2^{\circ} \mathrm{E}\right)$ at high latitudes, Juliusruh $\left(54.6^{\circ} \mathrm{N}, 13.4^{\circ} \mathrm{E}\right)$ in the buffer zone and Rome $\left(41.9^{\circ} \mathrm{N}, 12.5^{\circ} \mathrm{E}\right)$ at middle-to-low latitudes. The SIRM\&CCIR predictions in the following tests were obtained using the latest available prediction of R12 for each month in the test period. As the R12 predictions provided by SWPC/NOAA are updated on a monthly basis, one may argue that the results presented below represent best the accuracy of the model's predictions 1 month in advance. However, it is important to note that this approach ensures the fair evaluation of the limitations imposed by the modelling approach itself. Further limitations especially for longer term predictions (e.g. 2 or 3 months in advance) may be expected due to inaccuracies in R12 predictions. Therefore the evaluation of these longer term prediction maps is not a straightforward procedure and may result in misleading conclusions for the model's performance. Nevertheless, taking into account that: (i) the operational implementation of the adopted method provides prediction sensitivity when differences in R12 are larger than 10 units, and (ii) major updates of the solar cycle predictions are rather rare (e.g. the major update of Solar Cycle 24 prediction was released on May, 2009), it is argued that the results presented below may be considered indicative of the SIRM\&CCIR prediction accuracy in all prediction steps up to 3 months in advance.

As a first test, the time plots of the MM estimates and the SIRM\&CCIR predictions over each station are provided in Figure 4. By visual inspection it may be argued that the 


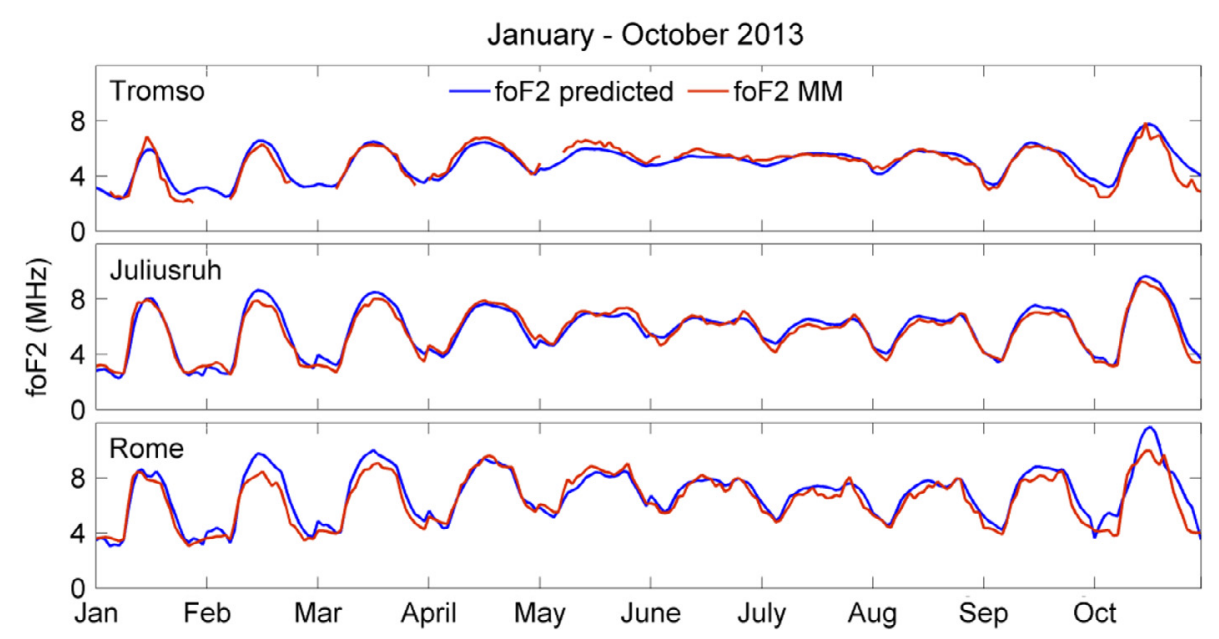

Fig. 4. Time plots of the foF2 SIRM\&CCIR and monthly median (MM) estimates for the time interval January-October 2013 over three European locations.

predictions reproduce successfully the diurnal and seasonal variation of the MM foF2 critical frequency and follow quite closely the observations. Then, the calculated Mean Error ( $\mathrm{ME}$ in $\mathrm{MHz}$ ), the Mean Relative Deviation (MRD\%), which is defined as the absolute difference of the predictions from MM divided by MM, and the Standard Deviation (STD\%) between the predicted and monthly median values of the observed foF2 were calculated and have been found to be $[\mathrm{ME}=0.07 \mathrm{MHz}, \mathrm{MRD}=8 \%, \mathrm{STD}=12 \%]$ for Tromso data, $[\mathrm{ME}=0.10 \mathrm{MHz}, \quad \mathrm{MRD}=6 \%, \quad \mathrm{STD}=8 \%]$ for Juliusruh data and $[\mathrm{ME}=0.34 \mathrm{MHz}, \quad \mathrm{MRD}=9 \%$, $\mathrm{STD}=10 \%$ ] for Rome data.

From the analysis above we can see no clear trend in the latitudinal performance of the enhanced SIRM. Statistical calculations show that the MRD does not exceed $10 \%$ in all cases and STD is around $10 \%$. This provides evidence of rather unbiased predictions. Moreover, the Mean Error ranges from 0.07 to $0.34 \mathrm{MHz}$ in all tests. Such statistical errors are in general comparable to the RMS errors calculated for the foF 2 model values of the Utah State University (USU) Global Assimilation of Ionospheric Measurements (GAIM) model for September 2006, for 21 ionosonde locations distributed around the world and found to be down to $0.5 \mathrm{MHz}$ at mid latitudes (McNamara et al. 2008).

\subsection{The enhanced version of the Simplified Ionospheric Regional Model Updated in Real-Time}

The nowcasting maps of the foF 2 released by EIS are based on the Simplified Ionospheric Regional Model Updated in realtime (SIRMUP), that has been enhanced to cover all European latitudes from $32^{\circ}$ to $80^{\circ}$.

The SIRMUP (Zolesi et al. 2004) is based on the Simplified Ionospheric Regional Model (SIRM), which is then updated with real-time ionospheric observations to update the climatological estimates to nowcasting services. SIRMUP is implemented in DIAS to produce nowcasting maps over Europe. SIRMUP uses real-time automatic scaled foF2 and $\mathrm{M}(3000) \mathrm{F} 2$ data from the ionosondes participating in the DIAS network to generate a new driving parameter of the SIRM, the effective sunspot number (Reff), calculated according to the Houminer et al. (1993) method. The Reff is chosen as the value that gives the best fit between the SIRM model output and the actual measurements obtained from the ionosondes located in the mapping area. The final outputs from the original SIRMUP nowcasting method are maps of foF2 and $\mathrm{M}(3000) \mathrm{F} 2$ covering the European area from $-5^{\circ} \mathrm{W}$ to $40^{\circ} \mathrm{E}$ in longitude and $34^{\circ} \mathrm{N}$ to $60^{\circ} \mathrm{N}$ in latitude. Two indicative nowcasting maps during negative and positive ionospheric storms are presented in Figure 5.

For the EIS, SIRMUP is enhanced to extend the mapping area to the high latitudes following the methodology adopted for the enhanced SIRM method:

- Application of SIRMUP algorithm between $34^{\circ} \mathrm{N}$ and $60^{\circ} \mathrm{N}$ in latitude (based on the SIRM) to calculate the Reff (denoted as Reff[foF2]mid in the EIS maps presented in Fig. 6) and the new coefficients for central and southern Europe.

- Application of the SIRMUP methodology at high latitudes between $50^{\circ} \mathrm{N}$ and $80^{\circ} \mathrm{N}$, based on the real-time autoscaled foF2 data from the reference stations and using the CCIR algorithm, instead of SIRM, to generate nowcasting predictions of foF2

- Interpolation between the two grids for the buffer zone, between $50^{\circ} \mathrm{N}$ and $60^{\circ} \mathrm{N}$.

As input parameters the model uses real-time foF2 measurements from middle and high latitude stations: Athens, Rome, Ebro, Arenosillo, Chilton, Juliusruh, Pruhonice, Moscow, Tromso and Sodankyla.

Figure 6 presents the nowcasting maps over the extended geographic area covered by the EIS service, corresponding to the same time epochs of the maps shown in Figure 5.

The SIRMUP nowcasting capabilities in the middle latitude ionosphere have been explored during quiet and disturbed ionospheric conditions by Zolesi et al. (2004) and Tsagouri et al. (2005) and the corresponding findings show, in general, a high degree of efficiency to map in real-time the propagation conditions over Europe. However, some possible limitations in the performance of the method were noted during localised ionospheric disturbances. This can be explained having in mind the logical structure of the model: by definition Reff is a regional index of ionospheric activity and its value depends 

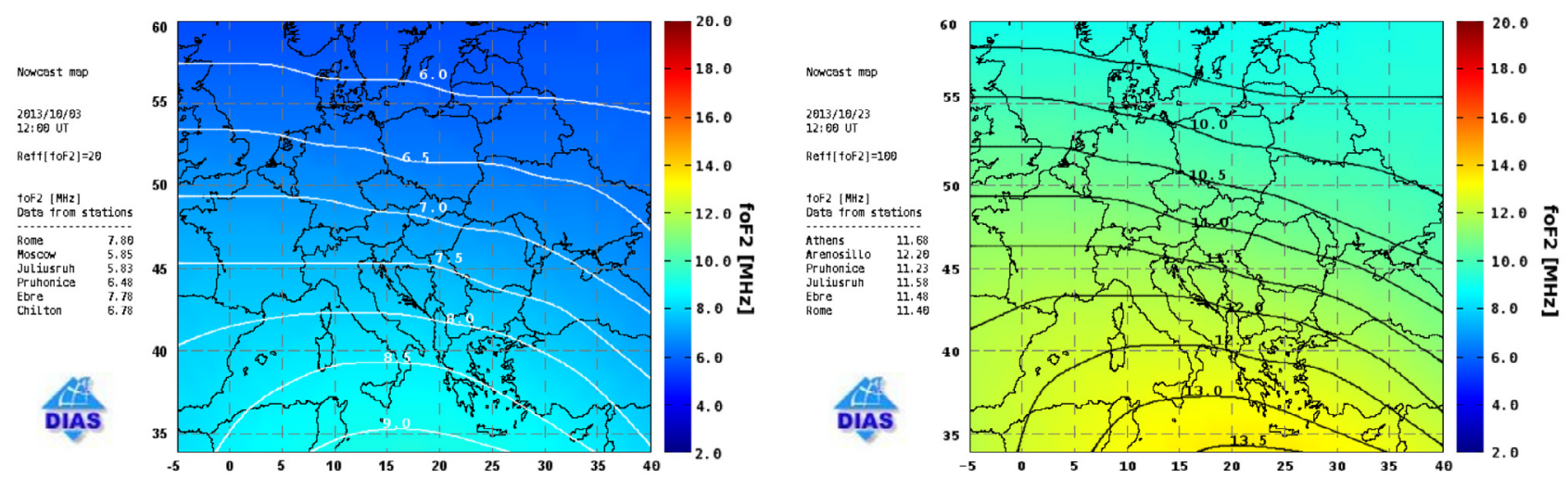

Fig. 5. Nowcasting maps calculated with the SIRMUP model released by the DIAS system. On the left side we present an example of a negative ionospheric effect triggered by a CME while on the right side we show a case of enhanced ionization due to pronounced solar flare activity.
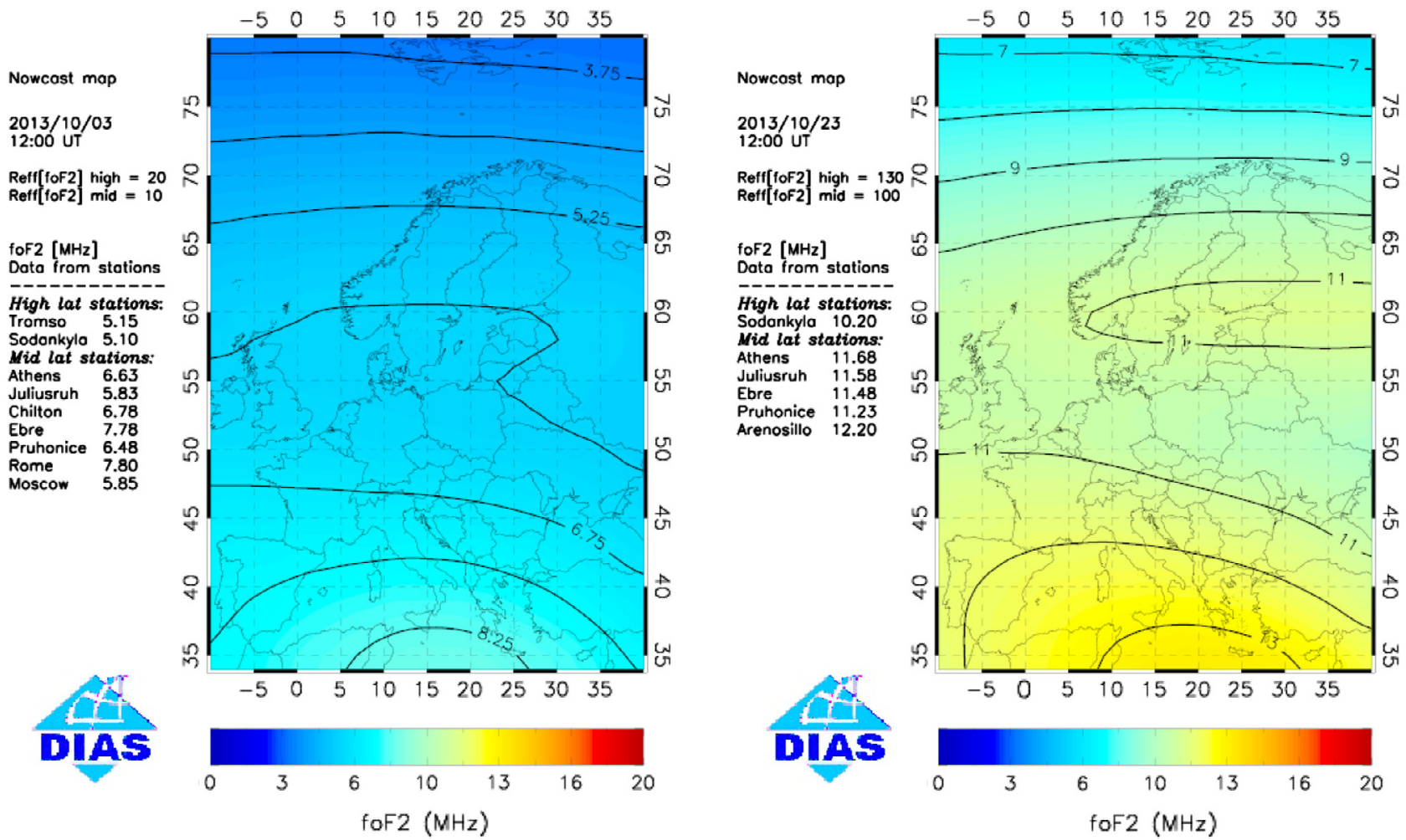

Fig. 6. Same as Figure 5, but for the extended geographic area that EIS covers. The maps here are generated using the enhanced SIRM (SIRMUP\&CCIR) method.

on the value of the automatic scaled foF 2 in the reference stations. Ionospheric disturbances caused by large-scale phenomena are usually correctly monitored in all stations of the mapping area and therefore reflected in the value of Reff. On the other hand, small-scale effects of a smaller range than the effective area of an ionospheric sounder are not imposed in Reff, unless the source of the disturbance is located near to the reference station. Further details on this problem are given by Zolesi et al. (2004).

To test the performance of the enhanced method (SIRMUP\&CCIR) we have analysed the model outputs from August 2013 until October 2013 in middle and high latitude locations. During this period, the geomagnetic activity ranged from quiet to moderate $(-100 \mathrm{nT}<$ Dst $<-50 \mathrm{nT})$, while the ionospheric activity reached levels greater than $50 \%$ in respect to the normal conditions, providing the opportunity to test the SIRMUP\&CCIR nowcasting capabilities under a representative set of ionospheric conditions.

For this purpose, foF2 autoscaled observations were systematically compared with SIRMUP\&CCIR nowcasts over three DIAS locations as in case of the long-term predictions: Tromso $\left(69.6^{\circ} \mathrm{N}, 19.2^{\circ} \mathrm{E}\right)$ as indicative station for high latitudes, Juliusruh $\left(54.6^{\circ} \mathrm{N}, 13.4^{\circ} \mathrm{E}\right)$ as indicative station for the buffer zone and Rome $\left(41.9^{\circ} \mathrm{N}, 12.5^{\circ} \mathrm{E}\right)$ as indicative station for middle-to-low latitudes. Moreover, foF2 observations from two test stations were also compared with 

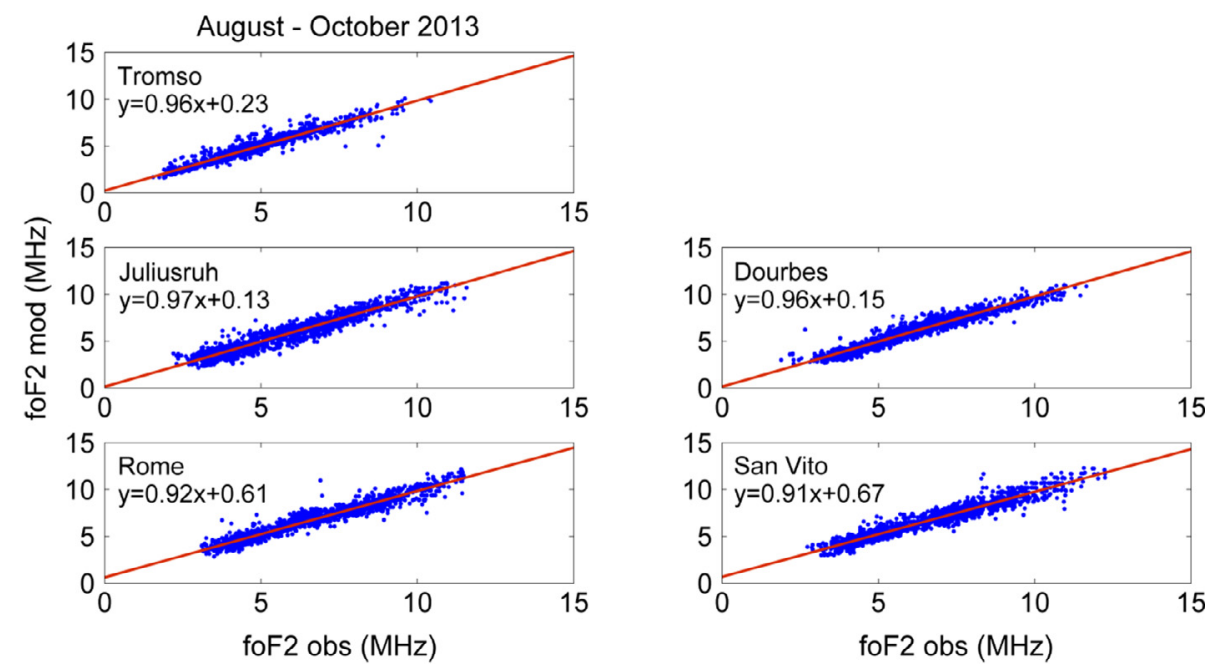

Fig. 7. The scatter plots of the SIRMUP\&CCIR foF2 nowcasts versus the foF2 observations over each location. Reference stations are on the left and test stations on the right of the figure.

Table 1. Accuracy and precision metrics estimates for SIRMUP\&CCIR output for the period August to October 2013.

\begin{tabular}{lccc}
\hline \hline Ionospheric Station & ME (MHz) & MRD (\%) & STD (\%) \\
\hline Tromso & 0.04 & 6.05 & 6.89 \\
Dourbes & -0.26 & 6.46 & 6.68 \\
Juliusruh & -0.54 & 8.35 & 7.75 \\
Rome & -0.21 & 6.60 & 6.53 \\
San Vito & -0.16 & 6.87 & 6.29 \\
\hline
\end{tabular}

SIRMUP\&CCIR nowcasts to assess independently the accuracy of EIS nowcasts: Dourbes $\left(50.1^{\circ} \mathrm{N}, 4.6^{\circ} \mathrm{E}\right)$ and San Vito $\left(40.6^{\circ} \mathrm{N}, 17.8^{\circ} \mathrm{E}\right)$.

As a first test the scatter plots of foF 2 nowcasts versus foF2 observations for the three reference and two test stations are presented in Figure 7. The results verify high correlation between modelled values and observations in all cases and comparable performance of the method in the middle and high latitudes. In particular, the results demonstrate similar performance in the middle-to-high and high latitudes, giving evidence for the validity of the enhancement of SIRMUP nowcasting capabilities in the high latitude ionosphere.

The accuracy and the precision of the nowcasts were then assessed through the estimation of three metric parameters as in the case of long-term predictions: the mean error (ME in $\mathrm{MHz}$ ), the mean relative deviation (MRD\%) and the standard deviation (STD\%). The results for each of the stations used in this analysis are provided in Table 1.

Nowcasting capabilities were further investigated during disturbed conditions. Figure 8 demonstrates the foF2 variation over Dourbes and San Vito as described by actual observations, SIRMUP\&CCIR, SIRM\&CCIR and MM during the geomagnetically disturbed period 1-4 October 2013. During this period a storm event of moderate intensity (min Dst $\sim 70 \mathrm{nT}$ ) produced significant ionospheric depletion effects on October 2 and October 3. The level of depletion was up to $40 \%$ and $30 \%$ in respect to monthly median conditions in Dourbes and San Vito, which is considered a significant disturbance,

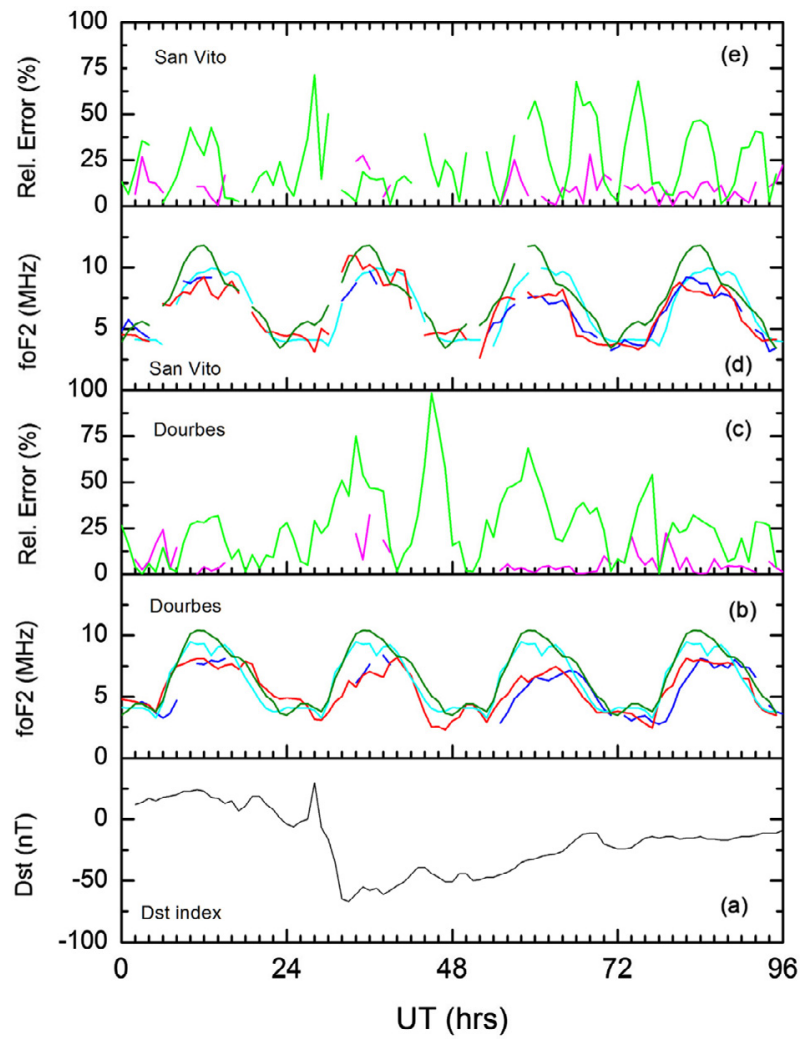

Fig. 8. Ionospheric response during the storm interval 1-4 October 2013. From bottom to top: (a) the Dst index, (b) the foF2 in Dourbes (red is the observed, blue is the SIRMUP\&CCIR model results, cyan is the monthly median, dark green is the SIRM\&CCIR predicted foF2), (c) the relative error of the observed foF2 over Dourbes in respect to the SIRMUP\&CCIR calculations (magenta) and the SIRM\&CCIR predictions (green), (d) the foF2 in San Vito (red is the observed, blue is the SIRMUP\&CCIR model results, cyan is the monthly median, dark green is the SIRM\&CCIR predicted foF2), (e) the relative error of the observed foF 2 over San Vito in respect to the SIRMUP\&CCIR calculations (magenta) and the SIRM\&CCIR predictions (green). 
A. Belehaki et al.: The European Ionosonde Service

Table 2. Metrics estimates for different configurations of the observational network at reference and test stations for the period 2001-2006.

\begin{tabular}{|c|c|c|c|c|c|c|c|c|c|}
\hline \multirow{2}{*}{$\begin{array}{l}\text { Experiment settings } \\
\text { Experiment 1: input data from } \\
\text { four stations }\end{array}$} & \multirow[t]{2}{*}{ Metrics } & \multicolumn{6}{|c|}{ Reference stations } & \multicolumn{2}{|c|}{$\begin{array}{c}\text { Independent test } \\
\text { stations }\end{array}$} \\
\hline & & \multicolumn{2}{|c|}{ Juliusruh } & \multicolumn{2}{|c|}{ Athens } & \multicolumn{2}{|c|}{ Chilton } & San Vito & Arenosillo \\
\hline $\begin{array}{l}\text { Missing station: a) Pruhonice; } \\
\text { b) Rome or Ebre }\end{array}$ & $\begin{array}{l}\text { MRD } \\
\text { STD } \\
\text { ME }\end{array}$ & \multicolumn{2}{|c|}{$\begin{array}{l}7.62 \\
5.68 \\
0.13\end{array}$} & \multicolumn{2}{|c|}{$\begin{array}{l}6.59 \\
5.54 \\
0.05\end{array}$} & \multicolumn{2}{|c|}{$\begin{array}{r}5.54 \\
5.36 \\
-0.07\end{array}$} & $\begin{array}{r}11.53 \\
13.47 \\
-0.19\end{array}$ & $\begin{array}{r}12.28 \\
13.95 \\
-0.17\end{array}$ \\
\hline $\begin{array}{l}\text { Experiment 2: input data from } \\
\text { five stations }\end{array}$ & & \multicolumn{2}{|c|}{ Juliusruh } & \multicolumn{2}{|c|}{ Athens } & \multicolumn{2}{|c|}{ Ebre } & San Vito & Arenosillo \\
\hline $\begin{array}{l}\text { Missing station: Pruhonice, } \\
\text { or Rome or Chilton }\end{array}$ & $\begin{array}{l}\text { MRD } \\
\text { STD } \\
\text { ME }\end{array}$ & \multicolumn{2}{|c|}{$\begin{array}{l}7.20 \\
6.87 \\
0.05\end{array}$} & \multicolumn{2}{|c|}{$\begin{array}{l}6.31 \\
5.26 \\
0.04\end{array}$} & \multicolumn{2}{|c|}{$\begin{array}{r}5.52 \\
5.78 \\
-0.12\end{array}$} & $\begin{array}{r}5.59 \\
4.79 \\
-0.12\end{array}$ & $\begin{array}{r}9.78 \\
7.99 \\
-0.04\end{array}$ \\
\hline \multirow{2}{*}{$\begin{array}{l}\text { Experiment 3: input data from } \\
\text { six stations }\end{array}$} & & Juliusruh & Athens & Chilton & Ebre & Pruhonice & Rome & San Vito & Arenosillo \\
\hline & $\begin{array}{l}\text { MRD } \\
\text { STD } \\
\text { ME }\end{array}$ & $\begin{array}{r}6.18 \\
5.50 \\
-0.02\end{array}$ & $\begin{array}{l}6.58 \\
5.64 \\
0.09\end{array}$ & $\begin{array}{r}5.57 \\
4.93 \\
-0.03\end{array}$ & $\begin{array}{l}5.28 \\
4.89 \\
0.00\end{array}$ & $\begin{array}{r}4.60 \\
4.17 \\
-0.01\end{array}$ & $\begin{array}{l}4.04 \\
3.09 \\
0.01\end{array}$ & $\begin{array}{r}4.97 \\
4.92 \\
-0.13\end{array}$ & $\begin{array}{r}9.52 \\
10.03 \\
0.03\end{array}$ \\
\hline
\end{tabular}

therefore the results are representative of the model's performance under disturbed conditions.

The SIRMUP\&CCIR results follow quite closely the observed values (comparison of the blue and red curves in Fig. 8) and succeed in reducing significantly the prediction error in respect to the background climatological estimates provided by the SIRM\&CCIR method or MM. In addition, the nowcasting error tends to be small (less than about $10 \%$ on average) for this specific event.

Two elements of special consideration in the assessment of the method's performance are the number and the distribution of the contributing stations. One should keep in mind that the SIRMUP algorithm as designed originally by Zolesi et al. (2004) requires data from at least four stations as input. Here it is attempted to investigate the method's relative performance under different configurations of the observational network, having as primary aim to determine quality indicators for the EIS products. However, to ensure representative results on the net effect of the changes in the configuration of the observational network, the effect of the autoscaling errors together with the effect of the ionospheric activity must be eliminated. For this purpose, the special experiments presented below, are based on the idea of using as input the median values instead of actual observations. The experiments were performed for the time period 2001-2006 that includes half of the previous solar cycle and therefore different levels of solar activity. The monthly median values of the foF 2 used here were obtained from actual observations received from 4 up to 6 reference stations: Chilton, Pruhonice, Juliusruh, Ebre, Rome, Athens. The method's predictions were then compared with the median values over the reference stations, but also over two independent test stations: San Vito and Arenosillo. The set of the stations that participate in each experiment was determined based on the availability of the data. To quantify the results the following metrics are used: the mean error (ME) and the mean relative deviation of the observed from the modelled median estimates (MRD\%) as an indication of the method's prediction accuracy and the corresponding standard deviation (STD\%) as an indication of the method's prediction precision. To quantify the relative performance between two test cases $i$ and $j$, the following skill score is applied:

$$
\begin{aligned}
& \% \text { accuracy improvement } \\
& \qquad=1-(\text { MRDtestcase } i / \text { MRDtestcase } j) .
\end{aligned}
$$

The obtained results are presented in Table 2 and based on the settings of the experiments one may argue that the metrics' estimates obtained here are also indicative for the performance of the method during ionospheric normal conditions.

To facilitate comparisons at the test stations the results are presented in a boxplot format in Figure 9 that includes a box and whisker plot for each case. The box has lines at the lower quartile, median (red line), and upper quartile values. Whiskers extend from each end of the box to the adjacent values in the data; in our case to the most extreme values within 1.5 times the interquartile range from the ends of the box. Outliers (e.g. data with values beyond the ends of the whiskers) are not displayed for visualization purposes.

Overall:

- The mean relative deviation and the standard deviation exceed $10 \%$ at the two test stations when data from four stations are considered as input (i.e. Experiment 1). The mean relative deviation is up to $10 \%$ in all other cases.

- Increasing the number of contributing stations increases the accuracy and the precision of the SIRMUP predictions. The \% accuracy improvement for the independent test stations is:

- Experiment 2 with respect to experiment 1: 20\% for Arenosillo and 51\% for San Vito;

- Experiment 3 with respect to experiment 2: 3\% for Arenosillo and $11 \%$ for San Vito. 


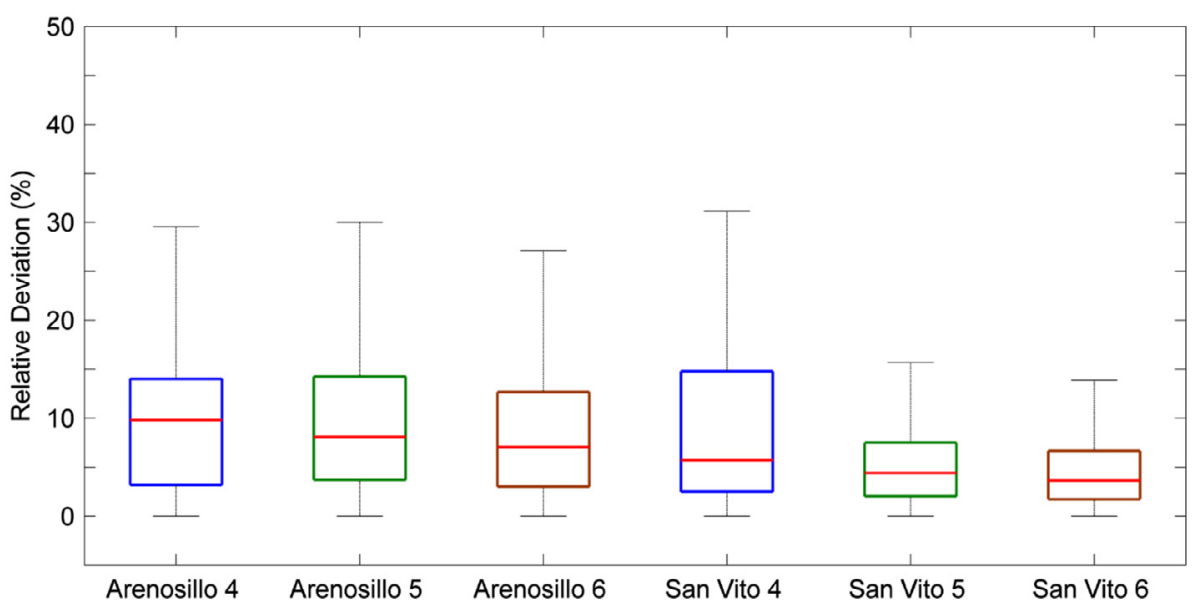

Fig. 9. The mean relative deviation of the observed from the modelled median estimates (MRD\%) over the two independent test stations, with the modelled median estimated using a variable number of reference stations $(4,5$ or 6$)$.

- There is more pronounced improvement for San Vito, which is located in the centre of the mapping area. This indicates that besides the number of the contributing stations, their distribution affects also strongly the method's performance.

- There is significant improvement between experiment 2 (5 stations) and experiment 1 (4 stations), while there is marginal improvement between experiment 3 (6 stations) and experiment 2 (5 stations).

Concluding, it is clear that the greater the number of stations included in the calculation of the Reff, the higher is the accuracy of the SIRMUP's predictions. Based on the MRD, the improvement may be locally up to $50 \%$ going from four to five stations and $10 \%$ further from five to six stations. The improvement is more pronounced in the centre of the mapping area, indicating that besides the number of contributing stations, their distribution affects also strongly the method's performance.

Based on the above discussion, the EIS provides to the users the following quality indicators for nowcasting services:

- The number and the distribution of stations contributing data for the generation of each map;

- The relative deviation of the nowcasted from observed values over the reference stations for each nowcasting map. An indicative example is given in Figure 10 for the estimates obtained on 1 December 2013, 13:00 UT. The relative deviation at each station is calculated according to the following simple formula (2):

$$
e=\left|\frac{\mathrm{foF} 2_{\mathrm{obs}}-\mathrm{foF} 2_{\mathrm{mod}}}{\mathrm{foF} 2_{\mathrm{obs}}}\right| \times 100,
$$

where foF $2_{\text {obs }}$ denotes the observed value and the foF $2_{\text {mod }}$ the modelled (nowcasted) one. Considering that the RMS error found by McNamara et al. (2008) between the USU-GAIM foF2 predictions and the observed values for mid-latitude stations was found to be down to $0.5 \mathrm{MHz}$, we propose that this should be considered as the threshold for acceptable predictions for this product too. This corresponds to a relative deviation $e$ (see Fig. 10) of $\sim 4.5 \%$ and

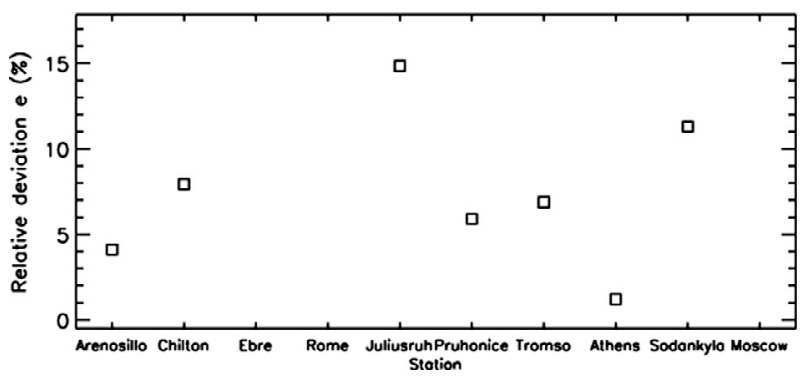

Fig. 10. The relative deviation of the nowcasted from observed foF 2 values over the reference stations is given as a quality indicator for EIS nowcasting services. The example presented here was obtained on 1 December 2013, 13:00 UT. In this example there are no data available from Juliusruh and Sodankyla stations, this is why there is no box sign plotted in the corresponding columns.

in this case the input value from the specific station is considered trustful for the model performance.

\subsection{Reconstruction of the topside electron density in real-time}

One of the main ESA requirements for the European Ionosonde Service was the development of a procedure that calculates TEC maps based on ionosonde data. To satisfy this request, we had to use a topside reconstruction model for the electron density profile (EDP) up to the GNSS heights and to apply a mapping procedure in order to transform single point EDP to 2D TEC maps. This development was based on the Topside Sounders Model - assisted by Digisondes ( $\mathrm{TaD})$. The $\mathrm{TaD}$ model is a topside profiler based on empirical equations derived from topside sounding data of the Alouette/ ISIS database and ingests the Digisonde observations at the height of the maximum electron density and the TEC parameters calculated from GNSS receivers at the Digisonde locations, to adjust the profiler with the real-time conditions of the ionosphere. The model has three components: (a) the Topside Sounders Model (TSM) subroutine (Kutiev \& Marinov 2007; Kutiev et al. 2006) that provides the empirical functions for the $\mathrm{O}^{+}-\mathrm{H}^{+}$transition height $\left(h_{\mathrm{T}}\right)$, the topside 
A. Belehaki et al.: The European Ionosonde Service

Table 3. The $\mathrm{TaD}$ subroutines for the topside reconstruction at a single point.

\begin{tabular}{lll}
\hline \hline Input parameters & \multicolumn{1}{c}{ Subroutine } \\
\hline Month, LT, glat, f10.7, & TSM: Topside Sounders Model & Empirical functions of parameters \\
Kp & Analytical functions based on & $H_{\mathrm{T}}:$ topside scale height $\left(\equiv H_{O^{+}}\right)$ \\
& Alouette, ISIS-1,-2 topside & $h_{\mathrm{T}}:$ transition height \\
& profiles (Bilitza 2001) & $R_{\mathrm{T}}:$ ratio $H_{\mathrm{T}} / h_{\mathrm{T}}$
\end{tabular}

$\begin{array}{ll}H_{\mathrm{m}}, k, R_{\mathrm{T}}, \mathrm{h}_{\mathrm{m}} \mathrm{F} 2, \mathrm{~N}_{\mathrm{m}} \mathrm{F} 2 & \text { TSMP: Topside Sounders Model } \\ \text { and glat } & \text { Profiler } \\ & \text { Analytical functions based on } \\ & \text { ISIS-1 topside profiles to model } \\ \text { plasmaspheric scale height }\end{array}$

Digisonde parameters at the height of maximum density (hmF2, foF2,

$\left.H_{\mathrm{m}}\right), R_{\mathrm{T}}$, and vTEC

(GNSS) at the

Digisonde location
TSM-assisted Digisonde Profiler Calculation of the actual profile over each Digisonde location to update TSMP with current Digisonde and TEC (GNSS) parameters

\section{Empirical functions of parameters}

$H_{\mathrm{P}}$ : plasmaspheric scale height $\left(\equiv H_{\mathrm{H}^{+}}\right), H_{\mathrm{P}}=H_{\mathrm{T}}\left(9 \cos ^{2}\right.$ glat +4$)$

$\mathrm{Ne}$ : electron density profile in the topside ionosphere and plasmasphere

$$
\begin{aligned}
& N e=N_{O^{+}}(h)+g N_{O^{+}}\left(h_{T}\right) \exp \left(-\frac{\left|h-h_{T}\right|}{H p}\right)+(1-g) N_{O^{+}}\left(h_{T}\right) \exp \left(-\frac{\left|h-h_{T}\right|}{4 H_{T}}\right) \\
& N_{O^{+}}(h)=N m \exp \left\{-\frac{1}{2}\left[\frac{h-h m}{k H m}+1-\exp \left(\frac{h-h m}{k H m}\right)\right]\right\} \\
& g \text { is the ratio } N_{\mathrm{H}+} / N_{\mathrm{O}^{+}} \text {at } h_{\mathrm{T}} \\
& k \text { is the correction parameter that converts } H_{\mathrm{m}} \text { (the neutral scale height) } \\
& \text { to make it compliant with } H_{\mathrm{T}}
\end{aligned}
$$

$$
N e=N_{O^{+}}(h)+g N_{O^{+}}\left(h_{T}\right) \exp \left(-\frac{\left|h-h_{T}\right|}{H p}\right)+(1-g) N_{O^{+}}\left(h_{T}\right) \exp \left(-\frac{\left|h-h_{T}\right|}{s k H_{m}}\right)
$$$$
\text { where } s=H_{\mathrm{He}+} / k H_{\mathrm{m}}
$$

The integral of the Ne profile can be adjusted to the measured vTEC by varying solely the correction parameter $k$ electron density scale height $\left(H_{\mathrm{T}}\right)$ and their ratio $R_{\mathrm{T}}=H_{\mathrm{T}} / h_{\mathrm{T}}$, derived solely from the Alouette/ISIS data; (b) the Topside Sounders Model Profiler (TSMP) subroutine (Kutiev et al. 2009a, 2009b) that offers analytical formulas for obtaining the shape of the vertical plasma distribution in the topside ionosphere and plasmasphere based on TSM parameters and on the $\mathrm{F}$ layer maximum density $(\mathrm{NmF} 2)$, its height $(\mathrm{hmF} 2)$ and its scale height $\left(H_{m}\right)$ at its lower boundary, derived from Digisondes. This profiler models separately the $\mathrm{O}^{+}, \mathrm{H}^{+}$and $\mathrm{He}^{+}$ density distributions in transition region between the topside $F$ region and plasmasphere, extracted from the analysis of the electron density profiles from ISIS-1; (c) the final TaD subroutine that performs the necessary transformations to the Digisonde autoscaled scale height so that the integrated TSMP electron density from the F layer peak to GNSS orbits can be finally adjusted to the measured GNSS TEC at the Digisonde location (Belehaki et al. 2012; Kutiev et al. 2012). A descriptive summary of the TaD model's components with their input and output parameters is given in Table 3.

The performance of the reconstruction subroutines over a single location has been verified through comparison with data from CHAMP and IMAGE/RPI missions, with ground-based GNSS-TEC parameters and with electron density profiles from Incoherent Scatter Radars (Belehaki et al. 2006b, 2009, 2012). Statistical comparison between the model predictions and Incoherent Scatter Radar electron density profiles collected at Malvern site from 1968 to 1971 resulted in a model error of 3TECU (1TEC Unit is TECU $=10^{16} \cdot \mathrm{m}^{-2}$ ) which is close to the measurement (GNSS) error (Belehaki et al. 2012). In addition, validation of the model results, based on comparison with ISIS1 electron density profiles, shows clearly (Belehaki et al. 2012) the model's ability to reproduce with impressive accuracy the ISIS1 EDP (98.8\%).

The TaD set of subroutines has been implemented in DIAS backend to provide maps of the electron density at predefined heights and maps of partial and total electron content, exploiting data streaming from the DIAS Digisondes in real-time. Operationally, the implemented code calculates first the maps of $H_{m}, \mathrm{hmF} 2$, and foF2 based on the available Digisonde data, applying the polynomial curve fitting for the mapping procedure. The $\mathrm{TaD}$ code reconstructs the three-dimensional map of the electron density distribution (3D-EDD) for all heights. Finally, the code adjusts the profiles with the TEC-GNSS parameters at the points where Digisonde measurements are available, and it recalculates the 3D-EDD maps. Values of the vertical TEC at the Digisonde locations are extracted by the TEC maps released by the GNSS team of the Royal Observatory of Belgium (ROB) based on the analysis of RINEX data files from the EUREF network (Bergeot et al. 2014). Based on this procedure, the following products are made available from the DIAS backend to the EIS user interface.

- Near real-time maps of the bottomside TEC based on Digisonde input and mapping. The bottomside TEC is the integrated electron density from $90 \mathrm{~km}$ to the hmF2 altitude.

- Near real-time maps of the topside TEC based on TaD model. The topside TEC is the integrated electron density from the hmF2 altitude up to the $\mathrm{O}^{+} / \mathrm{H}^{+}$transition height.

- Near real-time maps of plasmaspheric TEC based on $\mathrm{TaD}$ model. The plasmaspheric TEC is the integrated electron density from the $\mathrm{O}^{+} / \mathrm{H}^{+}$transition height up to $20,000 \mathrm{~km}$.

- Near real-time maps of the total TEC. The total TEC is the integrated electron density from $90 \mathrm{~km}$ up to $20,000 \mathrm{~km}$.

All the above products are available with a latency of up to 10 min with respect to real-time. 
At this point it is important to estimate the impact of the mapping procedure performance to the overall result. The weighted polynomial (Polyweight) procedure applied here, is a spatial interpolation method that can produce maps over any randomly spaced data, by calculating first values at the grid nodes $\left(1^{\circ} \times 1^{\circ}\right.$ geographic coordinates $)$ and then interpolating values between nodes by using a cubic interpolation method. Therefore, a point of investigation is the dependence of the accuracy of the predictions on the number of stations contributing with data for the calculation of each map.

Systematic comparisons are performed between the TaDcomputed TEC maps (NOA-TEC maps) and the GNSS-TEC maps provided by ROB. The ROB maps are produced by using 90-100 data points, while NOA maps are based on 4-8 data points provided by the available at the moment Digisonde stations. Comparison is aimed to give an estimate to what extent the NOA maps deviate from routine GNSS TEC maps. The results of this comparison are presented in Figure 11, where the distribution of the standard deviation (STD) as a function of the number of stations is given in a histogram format.

These results demonstrate that the number of contributing stations affects largely the performance of the mapping routine. As expected, the standard deviation between the $\mathrm{TaD}$ and GNSS TEC maps is almost doubled when the number of stations decreases from 6 to 4 . Consequently the number of contributing stations is an important parameter and therefore it is provided to the user as a performance indicator for this product.

One additional performance indicator is the Quality Index that characterises the average deviation between the $\mathrm{TaD}$ and the GNSS TEC grid and it is calculated according to the formula (3):

$$
\sqrt{ } \frac{1}{n-1} \sum_{i=1}^{n}(\text { TECm }- \text { TECo })^{2},
$$

where $n$ is the number of grid points, TECm denotes the TEC values calculated with the TaD model at each point of the grid and TECo denotes the GNSS TEC values at each point of the grid. The smaller the Quality Index is, the better the fit is between the GNSS calculated and the modelled maps. At this point it should be stressed that Quality Index is a relative measure of the agreement between the two grids and not an absolute measure of the correctness of the $\mathrm{TaD}$ calculated maps. In fact no direct way to measure the TEC exists. It should be considered that the GNSS TEC maps used here for comparison, as it is the case for all the TEC maps, are the result of model calculations, they are not direct measurements either and therefore are not error free. An analysis of the errors imposed in the GNSS mapping technique is provided by Bergeot et al. (2014).

An example showing the variability of the Quality Index is given in Figure 12a, that shows the daily plots of the observed foF2 (green), the fmin (yellow) and the predicted foF2 from SIRM (blue) from three stations, Juliusruh, Pruhonice, and Rome for 9 February 2014 (left side). The corresponding TEC maps calculated by EIS at 1445UT and 1500 UT are presented in Figure 12b (left side). During this quiet day the Quality Index is only 1.6 TECU, which indicates almost perfect fitting between the GNSS calculated and the modelled TEC maps. On the right side of Figures $12 \mathrm{a}$ and $12 \mathrm{~b}$ the

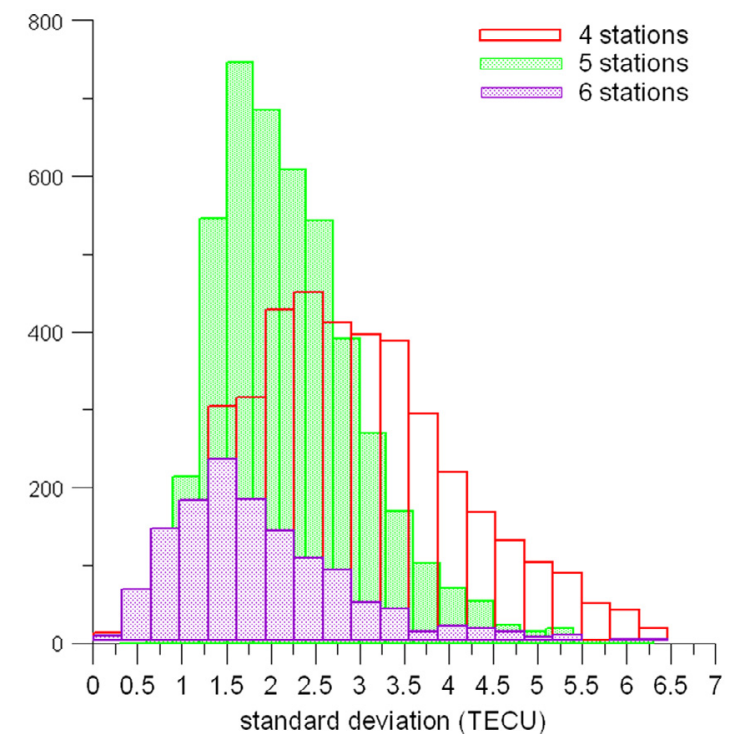

Fig. 11. The distribution of the STD between ROB (GNSS-TEC) and NOA (TaD-TEC) TEC maps as a function of the number of stations in a histogram format.

corresponding graphs for 20 February 2014 are presented. During the previous day a CME structure detected at L1 caused a positive ionospheric effect over the Europe sector, which is obvious from the foF 2 recordings at all stations. This is well reflected in the EIS TEC maps at 1445 UT and 1500 UT. However, the Quality Index has been increased considerably comparing to quiet conditions presented on the left side of this Figure. This is mainly due to autoscaling errors in some of the Digisondes, especially concerning the scale height parameter $H_{m}$. According to Kutiev et al. (2012) who analysed statistically the autoscaled values of the scale height, $H_{m}$, from all DIAS Digisondes $(1,163,564$ records in the DIAS database) from 2006 to 2010 , the values of $H_{m}$ above $40 \mathrm{~km}$ represent only $34 \%$ of all data. In $66 \%$ of cases, $H_{m}$ drops to very low values $(<40 \mathrm{~km})$, which is unrealistic. For the specific cases presented in Figure 12, the autoscaled values of $H_{m}$ at each contributing station are given in Table 4 .

Data presented in Table 4 show an anticorrelation between the mean value of the scale height over the contributing stations of a map and the Quality Index. During quiet conditions the autoscaled values of $H_{m}$ are in general above the $40 \mathrm{~km}$ threshold with the exception of Athens Digisonde that provided a scale height slightly lower that the accepted limit. During disturbed conditions for the 1,445 UT recordings we get outlier values in $H_{m}$ at three stations Athens, Ebre and Rome, causing a considerable increase of the Quality Index to 10.5 TECU. In the next sequence of ionograms recorded at 1,500 UT only Rome gave a very low value for $H_{m}$, but in addition, the average value of $H_{m}$ is in general low and close to the threshold. The Quality Index in this case has improved compared to the previous recordings, but is still high compared to quiet conditions. This discrepancy between observed (GNSS-TEC) and modelled values (TaD-TEC), as expressed by the Quality Index, is expected because for the adjustment of integral ED profile to measured TEC, the model is using a statistically pre-defined shape (Kutiev et al. 2012), which meet the current conditions, but cannot guarantee that this shape is exactly the real one. 
A. Belehaki et al.: The European Ionosonde Service
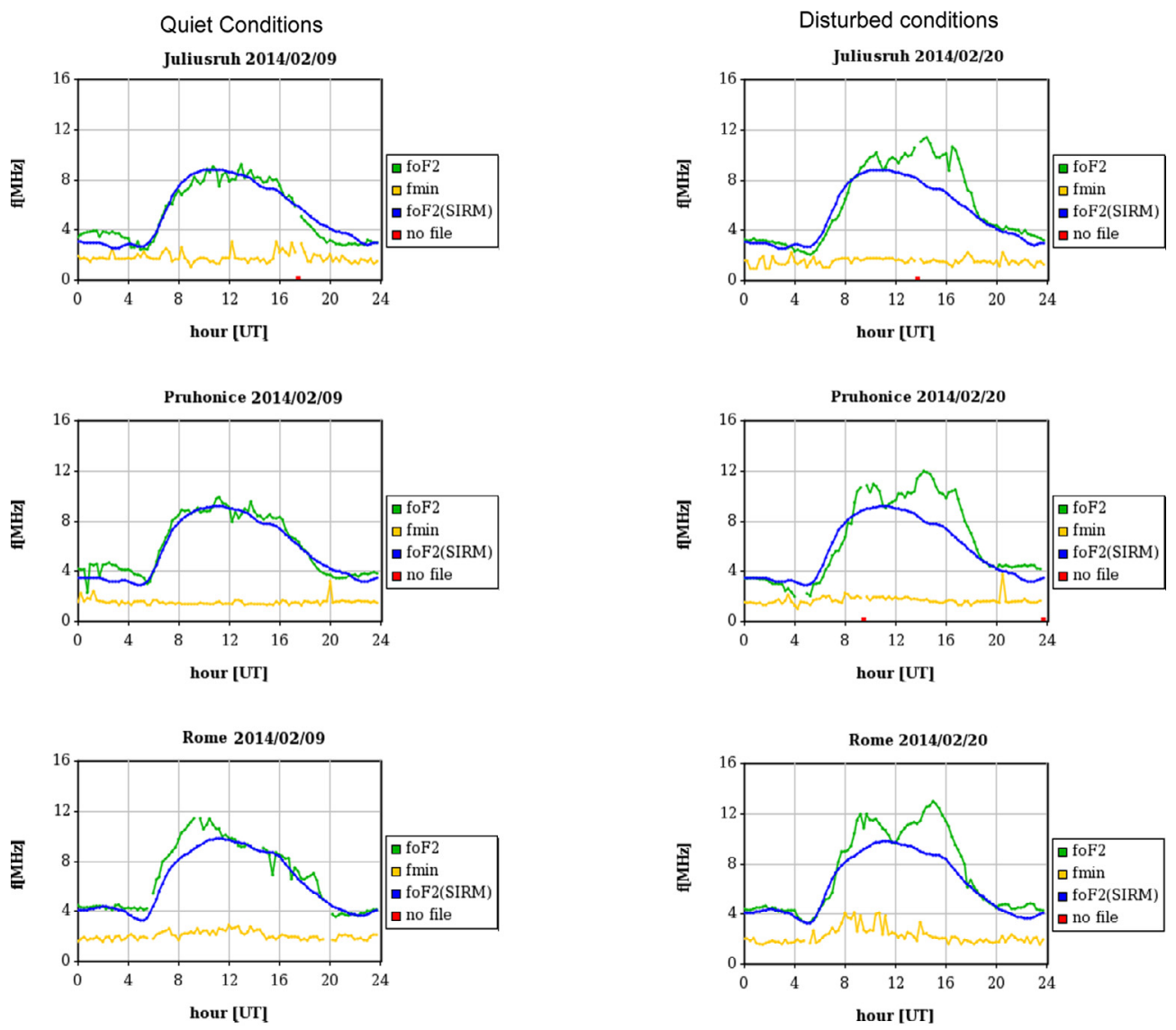

Fig. 12a. The ionospheric conditions over three DIAS stations during a quiet (left) and a disturbed day (right). The observed foF2 is plotted in green, the minimum critical frequency of the F-Layer (fmin) is plotted in yellow, while with blue we provide values of the foF 2 predicted with the SIRM model. The specific data presented in this example are not included in the SIRM fit.
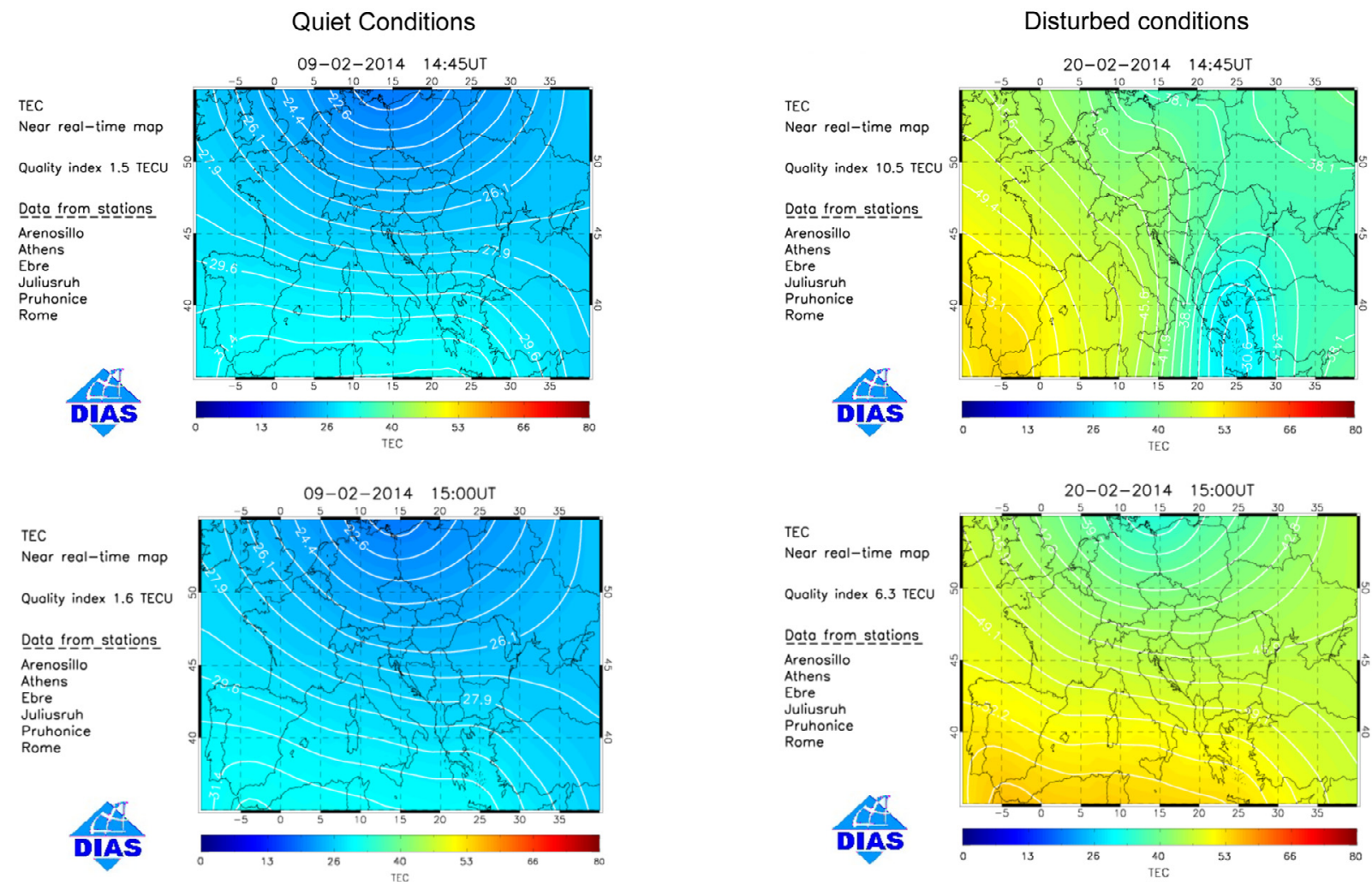

Fig. 12b. An example of the method's response during quiet and disturbed ionospheric conditions. 
Table 4. The values of the scale height $H_{\mathrm{m}}$ at hmF2, calculated by the Digisondes autoscaling software.

\begin{tabular}{|c|c|c|c|c|}
\hline & \multicolumn{2}{|c|}{9 February 2014 (quiet ionosphere) } & \multicolumn{2}{|c|}{$\begin{array}{c}20 \text { February } 2014 \text { (positive } \\
\text { ionospheric effect) }\end{array}$} \\
\hline & $1445 \mathrm{UT}$ & $1500 \mathrm{UT}$ & $1445 \mathrm{UT}$ & $1500 \mathrm{UT}$ \\
\hline Arenosillo & $73.2 \mathrm{~km}$ & $57.2 \mathrm{~km}$ & $49.0 \mathrm{~km}$ & $43.7 \mathrm{~km}$ \\
\hline Athens & $37.0 \mathrm{~km}$ & $35.6 \mathrm{~km}$ & $18.8 \mathrm{~km}$ & $40.3 \mathrm{~km}$ \\
\hline Ebre & $51.6 \mathrm{~km}$ & $54.9 \mathrm{~km}$ & $39.4 \mathrm{~km}$ & $45.4 \mathrm{~km}$ \\
\hline Juliusruh & $46.0 \mathrm{~km}$ & $46.0 \mathrm{~km}$ & $40.8 \mathrm{~km}$ & $43.8 \mathrm{~km}$ \\
\hline Pruhonice & $59.1 \mathrm{~km}$ & $49.3 \mathrm{~km}$ & $41.9 \mathrm{~km}$ & $42.2 \mathrm{~km}$ \\
\hline Rome & $40.2 \mathrm{~km}$ & $42.1 \mathrm{~km}$ & $32.9 \mathrm{~km}$ & $30.2 \mathrm{~km}$ \\
\hline Mean value of the scale height & $51.2 \mathrm{~km}$ & $47.5 \mathrm{~km}$ & $37.1 \mathrm{~km}$ & $40.9 \mathrm{~km}$ \\
\hline Quality Index & $1.5 \mathrm{TECU}$ & 1.6 TECU & 10.5 TECU & $6.3 \mathrm{TECU}$ \\
\hline
\end{tabular}

In summary the $\mathrm{TaD}$ subroutines demonstrate a number of capabilities:

1. The TaD computer code can support the near real-time release of EDD and partial TEC maps, as it can ingest and process in real-time Digisondes and GNSS-TEC parameters and calculates on the fly the corresponding maps.

2. A significant benefit of the $\mathrm{TaD}$ version implemented in EIS is that it facilitates the reliable reconstruction of the 3D-EDD in real-time. As shown by Kutiev et al. (2012), the adjustment of the modelled profile to the value of TEC calculated from ground-based GNSS receivers forces the model to correctly reproduce the topside scale height, despite the possibly inaccurate value of $H_{m}$. This adjustment is very important for the application of $\mathrm{TaD}$ in an operational environment.

3. Based on comparison with independent measurements of the electron density profiles from Malvern ISR (Belehaki et al. 2012), the average TaD model error at a single site location is found to be 3 TECU which is comparable to GNSS-TEC accuracy. Moreover as shown in Figure 11, the performance of the mapping $\mathrm{TaD}$ routine over the European area depends on the number of contributing Digisondes, with the average error compared to the corresponding GNSS-TEC maps ranging from 1.5 TECU (for 6 contributing Digisondes) to 2.5 TECU (for 4 contributing Digisondes).

4. The TaD software produces $3 \mathrm{D}$ EDD maps with altitude range from the E-layer up to $20,000 \mathrm{~km}$. Having the analytical function of the ED with height, it is possible to calculate its integral over portions of the whole altitudinal range. Hence for a satellite operator, it is possible to have the estimate of the integrated ED above the satellite at any moment. In addition, for scientific investigation purposes, TaD can facilitate studies of horizontal gradients and of vertical plasma redistribution processes in their time development, since it provides the 4D EDD over a specific region.

\subsection{The enhanced version of the Solar Wind Driven Autoregression Model for Ionospheric Short-term forecast}

EIS forecasting services are based on the enhanced version of the Solar Wind driven autoregression model for Ionospheric short-term Forecast (SWIF) developed by Tsagouri \&
Belehaki (2008), Tsagouri et al. (2009) and validated by Tsagouri (2011). Originally the model was developed and verified for forecasts at middle latitudes in Europe. For the needs of the European Ionosonde Service the model was extended to higher latitudes. Here we present the basic concept of the SWIF model and results for its performance over Europe for the latitudinal range from 32 to $80^{\circ} \mathrm{N}$.

SWIF combines real-time and past ionospheric observations with solar-wind parameters obtained in real-time at the L1 point by ACE spacecraft through the cooperation of a model that forecasts the non-storm ionosphere with the empirical Storm Time Ionospheric Model (STIM) formulating the ionospheric storm-time response based on solar wind input (Tsagouri \& Belehaki 2008). STIM predictions are triggered by an alert signal for upcoming ionospheric disturbances obtained from the analysis of the real-time observations of the interplanetary magnetic field (IMF), in particular, observations of the total magnitude $\mathrm{B}$ and the IMF-Bz component, from ACE spacecraft at L1. The alert algorithm is based on specific criteria that have been derived applying superposed epoch analysis on the magnetic field data from ACE for intense storm events occurred during solar cycle 23 . These events were mainly driven by CME-associated flows at L1 (Tsagouri \& Belehaki 2015). Upon the issuing of an alert, STIM estimates the time delay in the ionospheric storm onset for each geographic location as a function of the latitude and the local time (LT) of the station at the storm onset. The ionospheric storm time response is obtained by empirical expressions applied to the normal ionospheric variation. In no alert/storm conditions, SWIF results are typically those of the non-storm ionosphere model, while for ionospheric storm conditions STIM's predictions are progressively adopted for the whole of the disturbance as well as for $24 \mathrm{~h}$ after its end. SWIF recovers the full set of non-storm model predictions $24 \mathrm{~h}$ after the end of the ionospheric storm disturbance, which is determined by the STIM algorithm.

For the middle latitudes the non-storm ionosphere is modelled by applying the Time Series AutoRegressive (TSAR) model (Koutroumbas et al. 2008), which is an autoregression forecasting algorithm. At high latitudes the non-storm forecasts are provided by the CCIR model instead of TSAR because the later requires data from the past $24 \mathrm{~h}$ which are not often available from high-latitude Digisondes (Tsagouri \& Belehaki 2015). Ideally, the non-storm forecasts should be able to capture both normal and transient ionospheric variations induced by all relevant sources of influences, e.g. solar ionising flux, meteorological influences and solar wind conditions 
A. Belehaki et al.: The European Ionosonde Service

(a) Predictions efficiency vs time

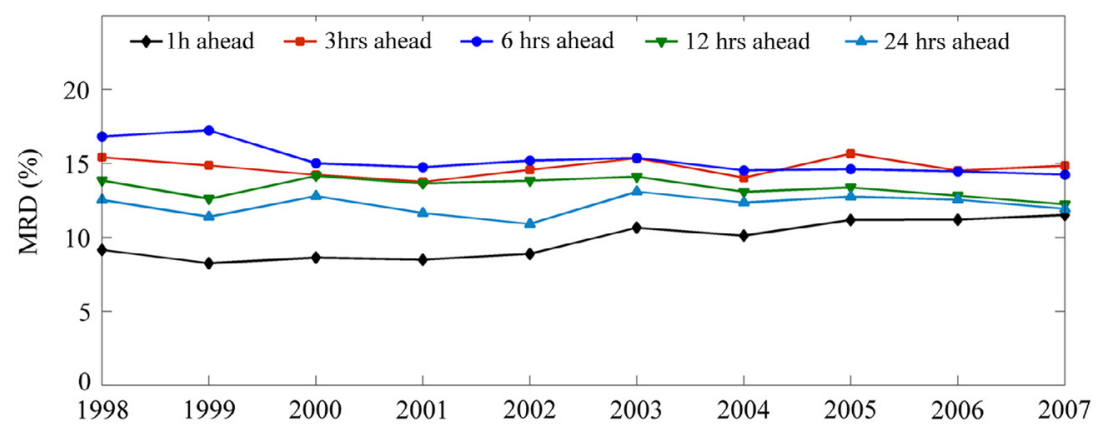

(b) Prediction efficiency vs prediction step

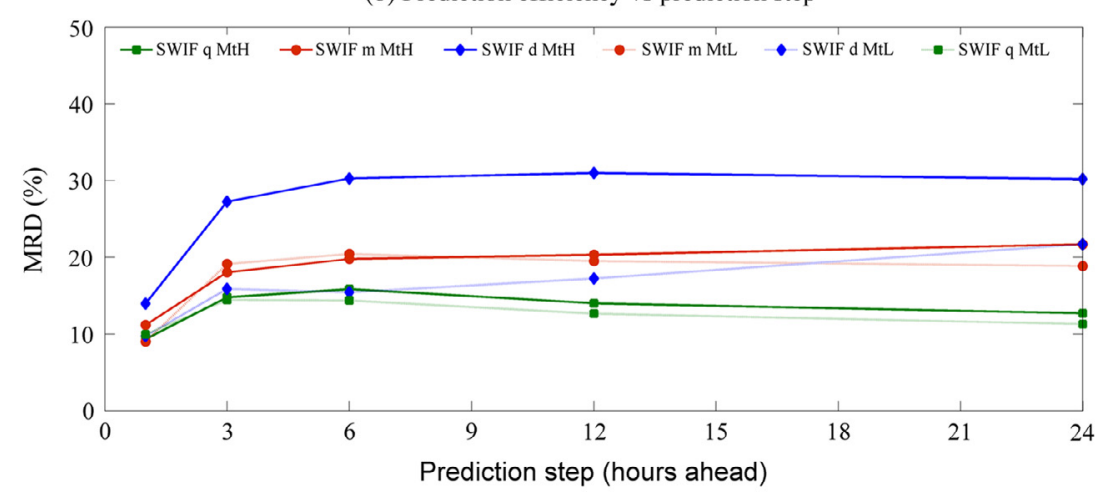

Fig. 13. The MRD (\%) between SWIF's forecasts and actual observations in respect to: (a) time, from 1998 to 2007 that corresponds to the temporal evolution of the solar cycle 23 and consequently to the solar activity level; and (b) geomagnetic activity level, latitude and prediction step (b) during solar cycle 23. The ionospheric activity level is indicated as "quiet (q)", "moderate (m) and "disturbed (d)", while the latitudinal dependence is explored in two latitudinal zones: middle-to-high (MtH) and middle-to-low (MtL).

(Forbes et al. 2000), excluding of course the storm-related variability. However, CCIR predictions are considered representative only for the normal ionospheric variation and therefore, some limitations are possible to be imposed on the SWIF's performance at high latitudes during non-storm conditions.

The performance of SWIF was systematically evaluated based on a metrics-based evaluation plan for middle latitudes (Tsagouri 2011) and for the whole European region including high latitude stations (Tsagouri \& Belehaki 2015). The foF2 predictions were systematically compared with actual observations over DIAS stations, also in comparison with standard prediction methods such as the monthly median values extracted by actual observations. The tests apply to solar cycles 23 and 24 and indicate unbiased performance of the model during these solar cycles. The relative improvement over median predictions - on average over all prediction steps from 1 up to $24 \mathrm{~h}$ ahead - is estimated to be about $29 \%$ in middle-to-low latitudes (less than $45^{\circ} \mathrm{N}$ ), $41 \%$ in middle-to-high latitudes (between 45 and $60^{\circ} \mathrm{N}$ ) and $31 \%$ at high latitudes (greater than $60^{\circ} \mathrm{N}$ ). Furthermore, it was found that the model's prediction accuracy depends on the prediction step, the level of the ionospheric activity and the latitude of the observation point especially during extremely disturbed conditions. Some indicative results are presented in Figure 13, where the MRD between SWIF's forecasts and actual observations is presented during solar cycle 23 (a) as a function of the year (top) for several prediction steps, and (b) as a function of prediction step for various levels of ionospheric activity and the latitude zones (bottom). The ionospheric activity level is indicated as "quiet (q)", "moderate (m)", and "disturbed (d)". Two latitudinal zones are considered, the Middle to Low (MtL) and the Middle to High (MtH). The results presented in Figure 13a are the yearly averages of the MRD for various prediction steps. It is obvious that in these results, predictions modelled by the TSAR model are the dominant ones, since the STIM component is activated only during storm conditions. TSAR being a pure autoregression model, especially during disturbed conditions, performs with decreasing accuracy for prediction steps up to $6 \mathrm{hrs}$ ahead, while for larger prediction steps the error recovers, as it is further analysed and demonstrated by Tsagouri (2011).

It is very important here to stress that the MRD for $1 \mathrm{~h}$ ahead predictions is at the level of $10 \%$ for all ionospheric activity levels and latitudinal zones. This indicates that if the $10 \%$ accuracy is sufficient for real-time operations, the 1-hr ahead SWIF predictions can be used for nowcasting purposes, in case the observed values arrive with a significant latency.

The enhanced version of SWIF provides three groups of products in EIS:

- Single site foF2 forecasts up to $24 \mathrm{~h}$ ahead

- Regional foF2 forecasting maps for the European region in collaboration with the new SIRMUP method adjusted to cover the whole European area

- Alerts and warnings for upcoming ionospheric storm disturbances for each DIAS location. The alerts include information on the forecasted onset of the disturbance, its duration and estimated deviation of the foF 2 from normal level 


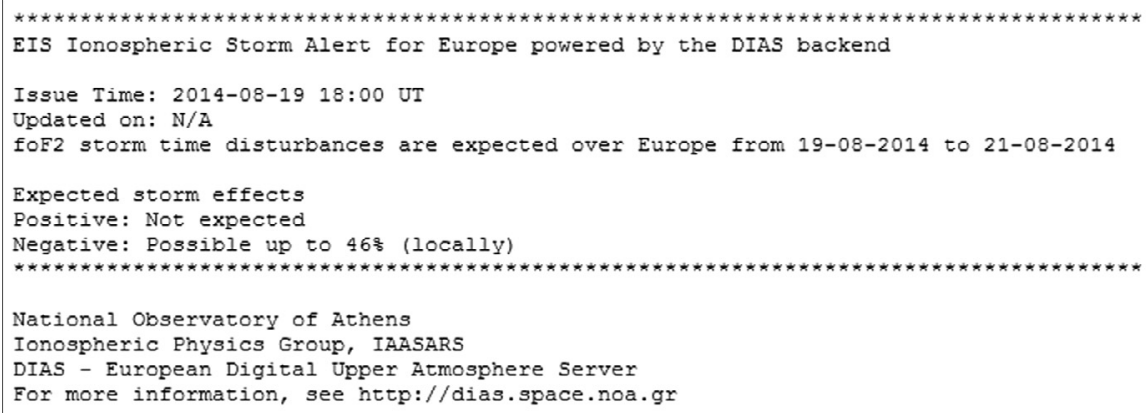

Fig. 14. The EIS alert message issued on 19 August 2014 at 18:00 UT.

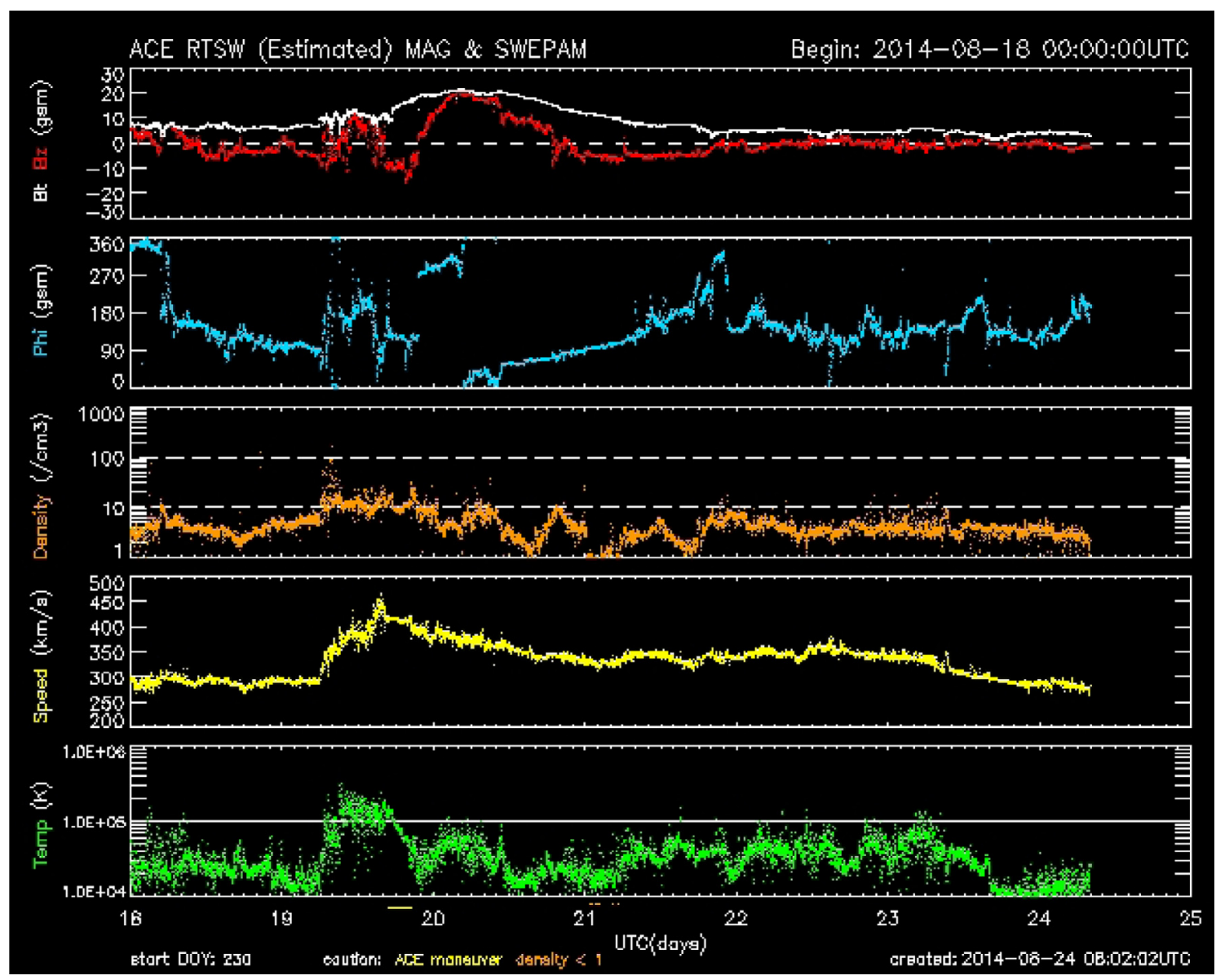

Fig. 15. The ACE recordings from 18 to 24 August showing the CME arrival recorded by the spacecraft on 19 August 2014.

The alert issued on 19 August 2014 at 18:00 UT (Fig. 14) is indicative of the model's performance. This alert seems to be triggered by a CME detected by ACE the same day (Fig. 15) and caused negative ionospheric effect over Europe. This was correctly forecasted by the SWIF algorithm, as seen by the individual foF2 predictions over individual stations of the DIAS network. SWIF predictions as released by DIAS are given in Figure 16. These plots were generated at 0500UT on 20 August 2014 and show the forecasts for the next $24 \mathrm{~h}$ (blue line) together with the reference value of the foF2 which is the running median for the middle latitude stations and the CCIR predictions for the high latitude station. The nowcasting maps released by EIS some hours after the alert (Fig. 17) confirm the validity of the forecast, since a decrease in the foF2 is observed over all European latitudes on 20 August 2014, in respect to the day before where ionospheric conditions were still undisturbed by the CME. The legend on the left side of each map, lists the observed values of the foF2 at each station used to calculate the specific map. Comparing the values of the foF 2 recorded at the quiet day (19 August, map presented on the right side of Fig. 17) and those recorded at the disturbed day (20 August, map presented on the left side of Fig. 17), but also comparing the two maps in general, it is obvious that on the 20 August the whole region is under the effect of a negative ionospheric storm. 
A. Belehaki et al.: The European Ionosonde Service
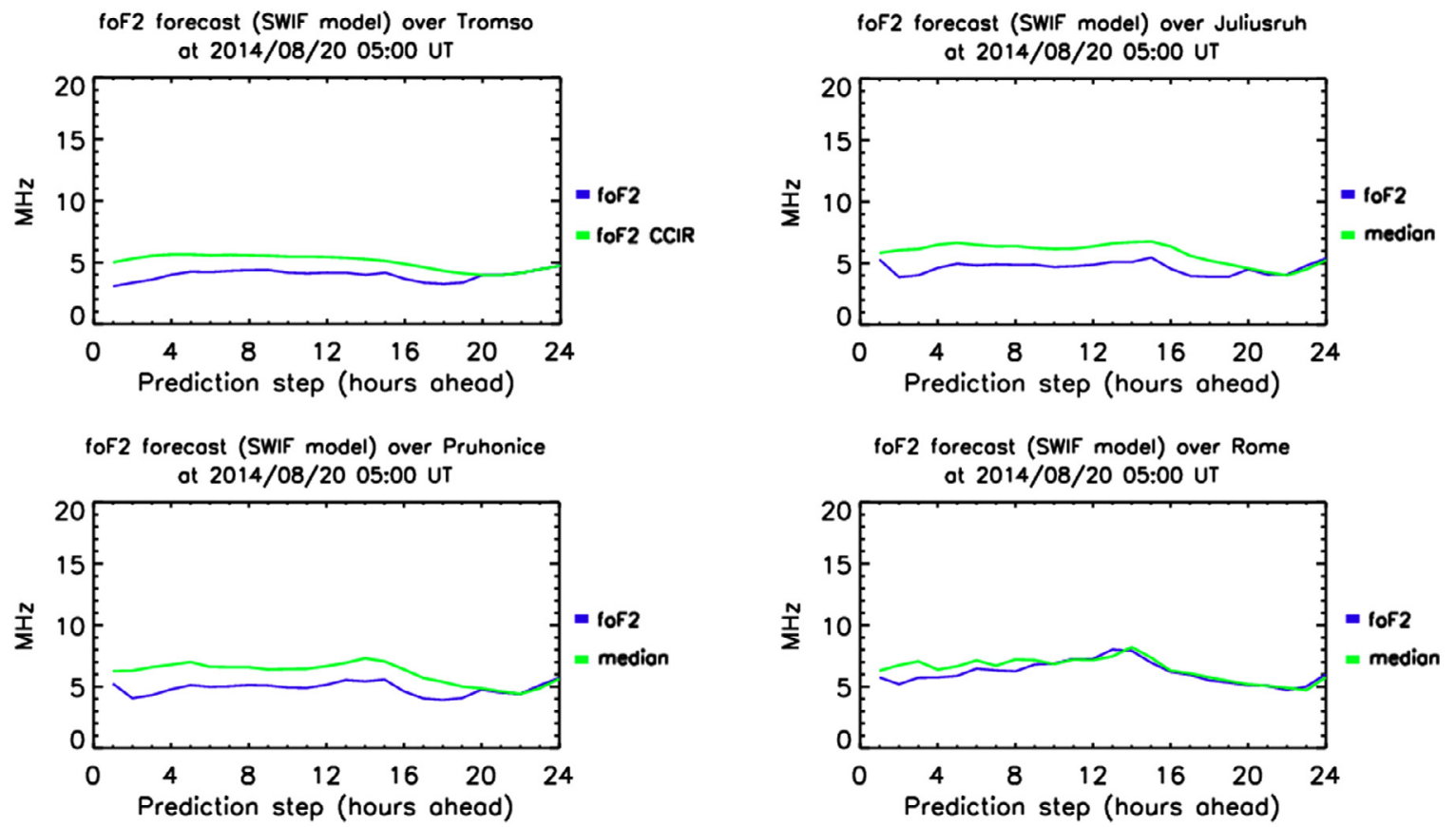

Fig. 16. The SWIF predictions issued by EIS on 20 August 2014 at 0500UT. Negative effect is forecasted at the middle-to-high latitude stations and a smaller effect over Rome (middle latitude).
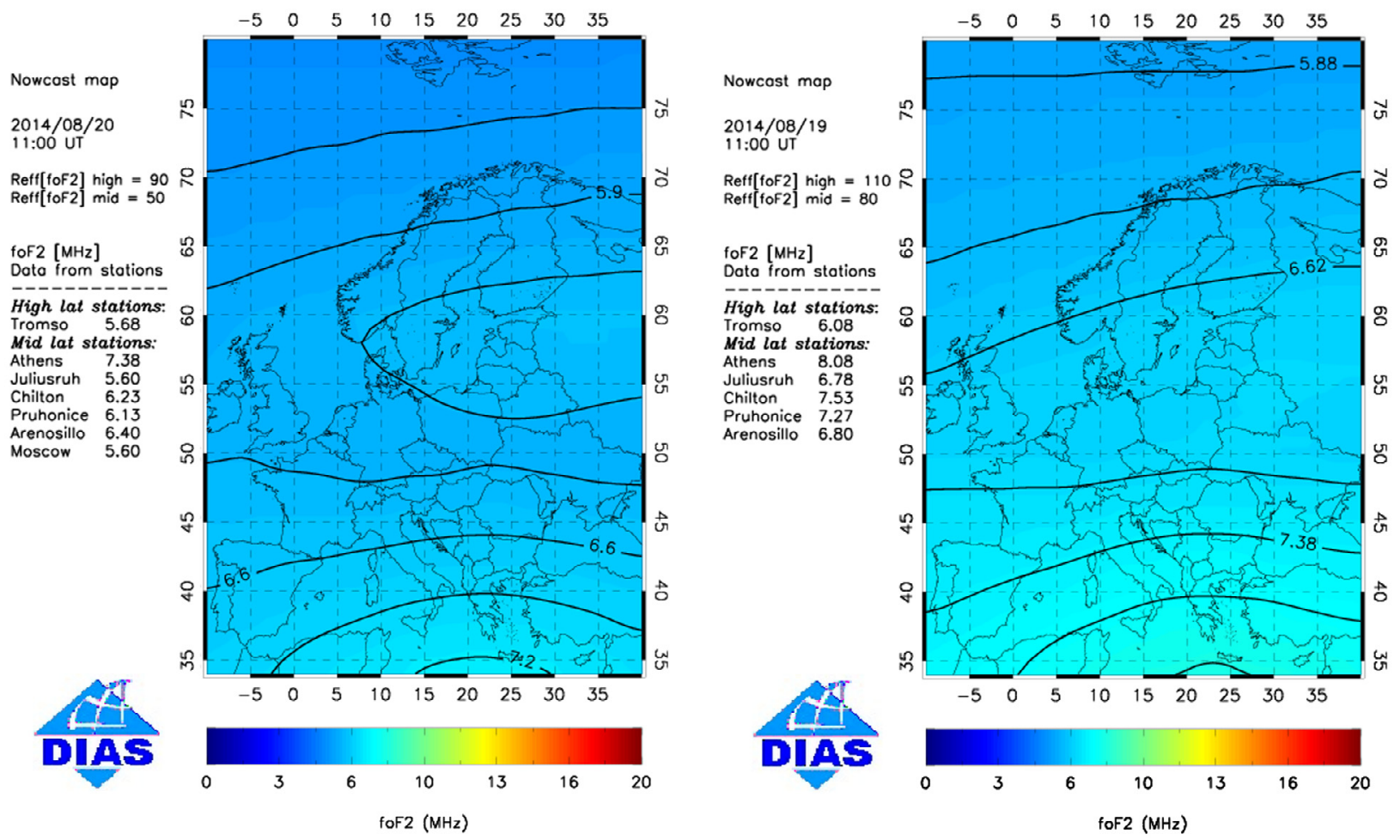

Fig. 17. Nowcasting maps released by EIS on 20 August 2014 (disturbed day) and on 19 August 2014 (quiet day), both at 1100 UT.

The successful performance of the SWIF model in this case is due to the fact that the ionospheric disturbance seems to be triggered by a CME arrival at L1 point. According to Tsagouri \& Belehaki (2015) $87 \%$ of the storm events taken into account in the development of the model were associated with the passage of interplanetary CMEs-mainly magnetic cloud and their associated sheaths, based on the classification of magnetic storms published by Echer et al. (2008). However for ionospheric disturbances caused by geomagnetic storms of moderate intensity, the performance indicators of SWIF model degrade significantly (Tsagouri \& Belehaki 2015), suggesting that the SWIF alert criteria need to be updated in the future 
in order to capture successfully ionospheric disturbances driven by other sources, i.e. high-speed streams and corotating interaction regions.

\section{The EIS assessment towards the ESA SSA customers requirements}

A main objective of the EIS is to release services designed to meet the requirements of the ESA customers, as these are listed in the ESA SSA Space Weather Customer Requirements Documents (ESA SSA Team 2011). These requirements are expressed in qualitative terms and aim to specify the type of the service. The EIS services, as all the SSA SWE federated services, are expected to result in an overall increase of the SSA service provision capacity.

A list of customers' requirements per service domain relevant to the EIS services is provided below, together with an analysis to assess how the EIS products can support these requirements.

\subsection{Transionospheric radio link}

- Estimation of ionospheric disturbance for ionospheric and transionospheric propagations: EIS provides two types of relevant products. The long-term predictions of foF2 which corresponds to background ionospheric conditions and the short term forecasts. A comparison of the two products can provide an estimate of the expected ionospheric disturbance over Europe for the next 24-h.

- Near real-time estimate of ionospheric and transionospheric propagation conditions: EIS provides a number of products that characterise bottomside and topside ionospheric conditions. For the bottomside, the user can consult the maps of foF 2 and the maps of the integrated electron content at the bottomside (bottomside TEC). The topside part is characterised by the maps of the integrated electron content at the topside (topside TEC) and at the plasmasphere (plasmaspheric TEC). For applications demanding knowledge of ionospheric conditions in real-time without any delay, the short-term forecasting of the foF 2 one hour ahead provides this information with a $10 \%$ uncertainty almost at all conditions (Fig. 13).

- Real-time TEC maps to estimate high level description of the state of the ionosphere: Maps of TEC are provided in near-real time by EIS, and currently cover the middle latitude European region.

\subsection{Spacecraft operation}

- Knowledge of the uncertainties caused by the ionosphere at least $1 \mathrm{~h}$ in advance: EIS provides the forecasted foF2 parameter for the next $24 \mathrm{~h}$ calculated with the SWIF model, and the mean relative error of the model for selected locations.

- Forecast and near real-time assessment of the effects of ionospheric disturbances: This requirement can be supported using the EIS forecasting and nowcasting products for foF2, partial TEC and TEC.

- Altitude-dependent TEC maps, for ionospheric correction for satellites with a single frequency GNSS receiver and in particular there is a requirement for the availability of TEC above the satellite: EIS provides in near real-time altitude-dependent TEC maps for the bottomside, the topside ionosphere and the plasmasphere. Upon user request the altitude of the TEC maps can be modified depending on the specific application requirements.

- Absolute measurements of electrons density height profiles (ionosonde data): This information is available at the DIAS backend, based on which the altitude dependent TEC maps (partial TEC) are calculated in EIS. Any user interested to receive the data in real-time can contact the EIS team.

- Forecasts with estimates of probability of occurrence of space weather events and of "All quiet conditions": This requirement can be satisfied with the combined use of space weather services that cover forecasts along the chain of processes starting from the Sun and ending in the upper atmosphere. EIS provides alerts for forthcoming ionospheric disturbances mainly triggered by geo-effective CMEs. As soon as an alert is issued, the user is able to know the expected magnitude of ionospheric disturbance over Europe, while at the same time short-term ionospheric forecasts can provide the local forecast for the next $24 \mathrm{~h}$, along with the model error.

\subsection{Spacecraft design}

- Estimate of the environment and its effects actually experienced: Although this is not on-line available, EIS operators can provide to spacecraft designers, upon request, statistical data regarding the foF2 variability, and the altitude-dependent TEC data over the locations of the DIAS stations for a time interval that covers the current and the previous solar cycles. In addition the long-term sustainability plan for EIS assures the longterm access to data and to model output, so that spacecraft designers can correlate spacecraft effects with environmental conditions. These correlations can be used to set alarms that will warn teams of adverse conditions. Also the assessment of hardware component behaviour under various space weather conditions is an important requirement for spacecraft designers that can be supported by EIS.

\subsection{General data service}

- Ionospheric alerts are in machine readable and human readable form to permit triggering of automated processing and/or post-event analysis: This requirement is fully supported by the EIS alert messages format, which is provided in a fixed format that can be read by a computer code.

- Definition of "all quiet conditions": This information can be extracted with the combined use of long term and nowcasting maps of the foF2, in case of no-alert conditions.

To facilitate the use of the EIS products, their main characteristics are summarised in Table 5. In the last column the quality indicators are given, where applicable. 
Table 5. Characteristics of the EIS products

\begin{tabular}{|c|c|c|c|c|c|c|}
\hline No. & Product & $\begin{array}{l}\text { Output } \\
\text { format }\end{array}$ & $\begin{array}{l}\text { Update } \\
\text { rate }\end{array}$ & Spatial Coverage & Data Input & Quality Indicator \\
\hline EIS1 & $\begin{array}{l}\text { Long term } \\
\text { predictions of foF2 } \\
\text { in the form of maps } \\
\text { over the whole } \\
\text { European region }\end{array}$ & $\begin{array}{l}\text { ASCII and } \\
\text { PNG }\end{array}$ & Monthly & $\begin{array}{l}\text { Europe: Regional } \\
\text { Longitude: }-10^{\circ} \mathrm{W}- \\
40^{\circ} \mathrm{E} \\
\text { Latitude: } 34^{\circ} \mathrm{N}- \\
80^{\circ} \mathrm{N}\end{array}$ & Predicted R12 & $\begin{array}{l}\text { Not applicable for } \\
\text { operational availability }\end{array}$ \\
\hline EIS2 & $\begin{array}{l}\text { Nowcasting } \\
\text { regional maps } \\
\text { showing the } \\
\text { variation of the } \\
\text { foF } 2 \text { critical } \\
\text { frequency over the } \\
\text { whole European } \\
\text { Region. }\end{array}$ & $\begin{array}{l}\text { ASCII and } \\
\text { PNG }\end{array}$ & Hourly & $\begin{array}{l}\text { Europe: Regional } \\
\text { Longitude: }-10^{\circ} \mathrm{W}- \\
40^{\circ} \mathrm{E} \\
\text { Latitude: } 34^{\circ} \mathrm{N}- \\
80^{\circ} \mathrm{N}\end{array}$ & $\begin{array}{l}\text { Real time foF2 } \\
\text { autoscaled values from } \\
\text { DIAS network }\end{array}$ & $\begin{array}{l}\text { Number and } \\
\text { distribution of stations } \\
\text { contributing data for } \\
\text { the generation of the } \\
\text { maps. } \\
\text { Relative deviation of } \\
\text { the nowcasts from } \\
\text { observed values over } \\
\text { DIAS stations. }\end{array}$ \\
\hline EIS3 & $\begin{array}{l}\text { Maps of the } \\
\text { forecasted foF } 2 \\
\text { parameter over } \\
\text { Europe for the next } \\
24 \mathrm{~h} \text {. }\end{array}$ & $\begin{array}{l}\text { ASCII and } \\
\text { PNG }\end{array}$ & Hourly & $\begin{array}{l}\text { Europe: Regional } \\
\text { Longitude: }-10^{\circ} \mathrm{W}- \\
40^{\circ} \mathrm{E} \\
\text { Latitude: } 34^{\circ} \mathrm{N}- \\
80^{\circ} \mathrm{N}\end{array}$ & $\begin{array}{l}\text { IMF-B and IMF-Bz } \\
\text { real time observations } \\
\text { at L1 point from ACE } \\
\text { Real-time and recent } \\
\text { past values of the foF2 } \\
\text { form DIAS network }\end{array}$ & $\begin{array}{l}\text { Relative deviation of } \\
\text { the mapped foF2 } \\
\text { values from the foF2 } \\
\text { forecasted values over } \\
\text { each station } \\
\text { (forecasted values over } \\
\text { each station location } \\
\text { are provided in EIS7). } \\
\text { This quality indicator } \\
\text { refers to the mapping } \\
\text { procedure and not to } \\
\text { the forecasted routine, } \\
\text { which is evaluated in } \\
\text { EIS7. }\end{array}$ \\
\hline EIS4 & $\begin{array}{l}\text { Near real-time TEC } \\
\text { maps for the } \\
\text { European region. }\end{array}$ & $\begin{array}{l}\text { ASCII and } \\
\text { PNG }\end{array}$ & $15 \mathrm{~min}$ & Europe: Regional & $\begin{array}{l}\text { (i) real time automatic } \\
\text { scaled SAO files } \\
\text { from all DIAS } \\
\text { Digisondes } \\
\text { (ii) TEC values from } \\
\text { EUREF (provided } \\
\text { by GNSS Group of } \\
\text { ROB) } \\
\text { (iii) daily F10.7 solar } \\
\text { flux, and } \\
\text { (iv) Three-hourly Kp } \\
\text { indices (forecasted } \\
\text { values). }\end{array}$ & $\begin{array}{l}\text { Number and } \\
\text { distribution of stations } \\
\text { contributing data for } \\
\text { the generation of the } \\
\text { maps. } \\
\text { The TEC maps are } \\
\text { characterised by a } \\
\text { quality index which is a } \\
\text { measure of the deviation } \\
\text { between the model and } \\
\text { the GNSS-derived TEC } \\
\text { parameters. The } \\
\text { smallest the quality } \\
\text { index is, the best is the } \\
\text { fit between the model- } \\
\text { derived maps and the } \\
\text { GNSS-derived TEC } \\
\text { maps. }\end{array}$ \\
\hline EIS5 & $\begin{array}{l}\text { Alerts for the } \\
\text { forthcoming } \\
\text { ionospheric } \\
\text { disturbances in the } \\
\text { European sector. }\end{array}$ & ASCII & $\begin{array}{l}\text { Whenever } \\
\text { an event } \\
\text { occurs }\end{array}$ & Europe: Regional & $\begin{array}{l}\text { IMF-B and IMF-Bz } \\
\text { real time observations } \\
\text { at } \mathrm{L} 1 \text { point from } \mathrm{ACE}\end{array}$ & $\begin{array}{l}\text { Not applicable for } \\
\text { operational } \\
\text { availability. }\end{array}$ \\
\hline EIS6 & $\begin{array}{l}\text { Maps of current } \\
\text { ionospheric } \\
\text { conditions at each } \\
\text { station location. }\end{array}$ & ASCII PNG & $15 \mathrm{~min}$ & Europe: Local & $\begin{array}{l}\text { Real time and past ( } 30 \\
\text { days) foF } 2 \text { values from } \\
\text { DIAS network of } \\
\text { stations }\end{array}$ & $\begin{array}{l}\text { foF2 observed values } \\
\text { foF2 running median } \\
\text { values } \\
\text { Number of days in the } \\
\text { estimation of median }\end{array}$ \\
\hline EIS7 & $\begin{array}{l}\text { Forecasted foF } 2 \\
\text { values for the next } \\
24 \mathrm{~h} \text { over each } \\
\text { station. }\end{array}$ & $\begin{array}{l}\text { ASCII and } \\
\text { PNG }\end{array}$ & Hourly & $\begin{array}{l}\text { Europe: Local/Single } \\
\text { stations }\end{array}$ & $\begin{array}{l}\text { IMF-B and IMF-Bz } \\
\text { real time observations } \\
\text { at L1 point from ACE } \\
\text { Real-time and recent } \\
\text { past values of the foF2 } \\
\text { form DIAS network }\end{array}$ & $\begin{array}{l}\text { Mean Relative Error } \\
\text { and Running Median } \\
\text { are available at the } \\
\text { main nodes of the } \\
\text { network. }\end{array}$ \\
\hline
\end{tabular}




\section{Conclusions and outlook}

The European Ionosonde Service is part of the Ionospheric Weather Services provided by the SSA SWE Portal. Two additional groups of services are available as part of the Ionospheric Weather Services, the Space Weather Application Center Ionosphere (SWACI) operated by the Deutsches Zentrum für Luft- und Raumfahrt e.V. (DLR) and the RealTime Ionospheric Monitoring service at high latitudes (RTIM) operated by the Norwegian Mapping Authority (NMA). SWACI (Jakowski et al. 2009, 2011) provides GNSS-based TEC maps in near-real time and one hour in advance, for the European region, and the slab thickness and scintillation index over specific locations. RTIM offers nowcasting services for the ionospheric plasma conditions and its irregularities over the Nordic region (Jacobsen \& Schäfer 2012). It is evident that the three groups of services, EIS, RTIM, and SWACI, are fully complementary and therefore are addressing different user requirements for the European region.

EIS offers unique services for ionospheric propagation and for nowcasting trans-ionospheric conditions which are useful for GNSS, radio applications and satellite operators and designers. Especially the TEC maps is a key product derived from the integration of the EDD over the whole altitude range from the E-layer up to $22,000 \mathrm{~km}$. Therefore for future applications, EIS can also provide partial TEC maps for any altitudinal range. This can be valuable for satellite operators who wish to know the TEC above their satellite, and good prospects exist for improving this product regarding both accuracy (currently is 3TECU as demonstrated by the independent validation performed by Belehaki et al. 2012) and output format (e.g. release of 3D electron density distribution over Europe). Some efforts have been already implemented by Marinov et al. (2015) where a multivariable function for the ionospheric and plasmaspheric scale height is proposed to be introduced in the $\mathrm{TaD}$ in order to increase the accuracy of the resulting ED profiles.

Further developments are possible, and even necessary, considering the customers' requirements. These developments concern the underlying algorithms and the overall infrastructure.

Improved algorithms producing the forecasted values of the critical frequency foF2 for the next $24 \mathrm{~h}$ : The model, currently implemented in EIS, predicts ionospheric disturbances driven by CME magnetic signatures at L1 point. This can be considerably improved if the model takes into account the effects of solar flares and of high-speed solar wind streams. This problem is very complicated and can be approached through the development and analysis of statistical disturbance maps of the Sun-Earth system based on the analysis of space and ground-based data from the whole Sun-Earth interaction chain (solar, interplanetary, magnetospheric, geomagnetic and ionospheric). This is expected to result in the issuing of ionospheric alerts with higher hits rate and less misses.

Furthermore, alternative proxies can be defined to trigger the model in order to become independent from the ACE mission at L1 but also in order to increase the prediction efficiency. Possible proxies can be solar flare forecasts, the forecasted geomagnetic field disturbances from auroral oval magnetograms and the proton flux in the polar cusp. This is expected to result to a shorter warning time but higher prediction accuracy.
Improved algorithms for the topside reconstruction model applied for the calculation of the TEC maps: Possible developments include

(a) the implementation of an advanced version of the $\mathrm{TaD}$ model for the reconstruction of the vertical structure of the electron density over a single point, applying a multi-parametric function to model the plasmaspheric scale height;

(b) improvements of the mapping technique over a specific area, to increase the latitudinal/longitudinal accuracy of the model; this will result in latitude/longitude high precision 3D electron density distribution maps. The improved technique can be validated first for the European region and then it can be applied to the American sector, where the source code (TaD) has been proven to work with higher accuracy because of the good availability of the computed ISIS-1 profiles available from the ISIS/Alouette Topside Sounder Data Restoration project (http://nssdc.gsfc.nasa.gov/space/ isis/isis-status.html) and the Near-Earth Space Data Infrastructure for e-Science (ESPAS) portal, http:// www.espas-fp7.eu;

(c) specification of travelling ionospheric disturbances proxies and application of the GPS radio interferometer technique to identify the characteristics of travelling ionospheric disturbances. Their effects at the various layers of the ionosphere can be derived by analysing the variation of the partial electron density integrals over specific height ranges.

In summary the improved and new sets of products that can result from these additional developments are:

- Improved forecasted maps of the foF2 over Europe and improved ionospheric alerts.

- High accuracy maps of TEC and of the partial integrals of the electron density over user-defined height ranges.

- A warning system for identification and tracking of Travelling Ionospheric Disturbances (TID).

An important element to support such improvements is the operation of an advanced network of DPS-4D Digisondes in Europe able to operate in bi-static links mode and therefore to monitor and analyse in real-time ionospheric wave structures and calculate in high temporal and spatial resolution the electron density in 3D over Europe. Such a network has started to be designed and deployed in Europe and it is estimated to be operational in 2017.

Acknowledgements. The European Ionosonde Services are based on the real-time availability of data from the Observatorio del Ebre in Spain, the Institute for Atmospheric Physics in Czech Republic, the Juliusruh Observing Station of the Leibnitz University in Germany, the INTA in Spain, the STFC-RAL in UK, the GIRO database of the University of Massachusetts Lowell in USA, the IZMIRAN in Russia, the Sodankyla Geophysical Observatory in Finland and the GNSS group of the Royal Observatory of Belgium. The INGV team is grateful to Adriano Azzarone, Ljiljana Cander and Luigi Ciraolo for fruitful collaboration. This work is part of the ESA SSA Contract No. 4000106756/12/D/MRP. AB acknowledges EOARD support through Grants FA8655-12-1-0004 and FA955014-1-0080.

The editor thanks three anonymous referees for their assistance in evaluating this paper. 


\section{References}

Alexander, P., A. de la Torre, R. Hierro, and P. Llamedo. Assessment of precision in ionospheric electron density profiles retrieved by GPS radio occultations. Adv. Space Res., 54 (11), 2249-2258, 2014, DOI: 10.1016/j.asr.2014.08.029.

Allain, D.J., and C.N. Mitchell. Ionospheric delay corrections for single-frequency GPS receivers over Europe using tomographic mapping. GPS solutions, 13 (2), 141-151, 2009.

Angling, M.J., and N. Jackson-Booth. A short note on the assimilation of collocated and concurrent GPS and ionosonde data into the Electron Density Assimilative Model. Radio Sci., 46, 1-7, 2011, DOI: 10.1029/2010RS004566.

Belehaki, A., L. Cander, B. Zolesi, J. Bremer, C. Juren, I. Stanislawska, D. Dialetis, and M. Hatzopoulos. DIAS Project: the establishment of a European digital upper atmosphere server. J. Atmos. Sol. Terr. Phys., 67, 1092-1099, 2005.

Belehaki, A., Lj. Cander, B. Zolesi, J. Bremer, C. Juren, I. Stanislawska, D. Dialetis, and M. Hatzopoulos. Monitoring and forecasting the ionosphere over Europe: the DIAS project. Space Weather, 4, S12002, 2006a, DOI: 10.1029/2006SW000270.

Belehaki, A., P. Marinov, I. Kutiev, N. Jakowski, and S. Stankov. Comparison of the topside ionosphere scale height determined by topside sounders model and bottomside digisonde profiles. $A d v$. Space Res., 37, 963-966, 2006b.

Belehaki, A., Lj. Cander, B. Zolesi, J. Bremer, C. Juren, I. Stanislawska, D. Dialetis, and M. Hatzopoulos. Ionospheric specification and forecasting based on observations from European ionosondes participating in DIAS project. Acta Geophys., 55 (3), 398-409, 2007, DOI: 10.2478/s11600-007-0010-x.

Belehaki, A., I. Kutiev, B. Reinisch, N. Jakowski, P. Marinov, I. Galkin, C. Mayer, I. Tsagouri, and T. Herekakis. Verification of the TSMP-assisted Digisonde ( $\mathrm{TaD})$ topside profiling technique. Acta Geophys., 58 (3), 432-452, 2009a.

Belehaki, A., J. Watermann, J. Lilensten, A. Glover, M. Hapgood, M. Messerotti, R. van der Linden, and H. Lundstedt. Renewed support dawns in Europe: an action to develop Space Weather products and services. Space Weather, 7, S03001, 2009b.

Belehaki, A., I. Tsagouri, I. Kutiev, P. Marinov, and S. Fidanova. Upgrades to the Topside Sounders Model assisted by Digisonde $(\mathrm{TaD})$ and its validation at the topside ionosphere. J. Space Weather Space Clim., 2, A20, 2012, DOI: $10.1051 / \mathrm{swsc} / 2012020$.

Belehaki, A., M. Messerotti, and M. Candidi. Developing space weather products and services in Europe - preface to the special issue on COST Action ES0803. J. Space Weather Space Clim., 4, E1, 2014, DOI: 10.1051/swsc/2014032.

Bergeot, N., J.-M. Chevalier, C. Bruyninx, E. Pottiaux, W. Aerts, Q. Baire, J. Legrand, and P. Defraigne. Near real-time ionospheric monitoring over Europe at ROB using GNSS data. J. Space Weather Space Clim., 4, A31, 2014, DOI: 10.1051/swsc/2014028.

Bilitza, D. International Reference Ionosphere (IRI) - Task Force Activity Report 2000. IRI News, 8 (1/2), 8-15, 2001.

Bourdillon, A., B. Zolesi, and Lj.R. Cander. COST 296 action results for space weather ionospheric monitoring and modeling. Adv. Space Res., 45 (9), 1173-1177, 2010, DOI: 10.1016/j.asr.2009.11.024.

Bradley, P. Review of COST 238 (PRIME) achievements, IEE Colloquium on HF Antennas and Propagation, 7/1-7/6, 1995, DOI: $10.1049 /$ ic: 19951275.

Comberiate, J., and L.J. Paxton. Coordinated UV imaging of equatorial plasma bubbles using TIMED/GUVI and DMSP/ SSUSI. Space Weather, 8, S10002, 2010, DOI: $10.1029 / 2009$ SW000546.

Echer, E., W.D. Gonzalez, B.T. Tsurutani, and A.L.C. Gonzalez. Interplanetary conditions causing intense geomagnetic storms (Dst $\leq-100 \mathrm{nT}$ ) during solar cycle 23 (1996-2006). J. Geophys. Res., 113, A05221, 2008, DOI: 10.1029/2007JA012744.

ESA SSA Team. Space Situational Awareness - Space Weather Customer Requirements Document (http://swe.ssa.esa.int/DOCS/ SSA-SWE/SSA-SWE-CRD-1001_i4r3.pdf), 2011.
Forbes, J.M., S.E. Palo, and X. Zhang. Variability of the ionosphere. J. Atmos. Sol. Terr. Phys., 62, 685-693, 2000.

Galkin, I., G.M. Khmyrov, A.V. Kozlov, B.W. Reinisch, X. Huang, and V.V. Paznukhov. The ARTIST 5. Radio Sounding and Plasma Physics, AIP Conf. Proc., 974, 150-159, 2008, DOI: $10.1063 / 1.2885024$

Galkin, I., B.W. Reinisch, X. Huang, and G.M. Khmyrov. Confidence Score of ARTIST-5 Ionogram Autoscaling, INAG Technical Memorandum, November 25, 2013, http://www.ursi.org/ files/CommissionWebsites/INAG/web-73/confidence_score.pdf

Goodman, J.M. Space Weather \& Telecommunications, The Kluwer International Series in Engineering and Computer Science, Springer Science + Business Media, Inc, ISBN: 0-387-23670-8 (HC) ISBN: 0-387-23671-6 (eBook), 2005.

Hanbaba, R., and B. Zolesi. Improved Quality of Service in Ionospheric Telecommunication Systems Planning and Operation: COST 251 major achievements. Fisica de la Tierra, 1, 61-103, 2000.

Hernandez-Pajares, M., J. Miguel Juan, J. Sanz, A. Aragon-Angel, A. Garcia-Rigo, D. Salazar, and M. Escudero. The ionosphere: effects, GPS modeling and the benefits for space geodetic techniques. J. Geod., 85, 887-907, 2011, DOI: $10.1007 / \mathrm{s} 00190-011-0508-5$.

Houminer, Z., J.A. Bennett, and P.L. Dyson. Real-time ionospheric model updating. Journal of Electrical and Electronics Engineering, 13 (2), 99-104, 1993.

Jacobsen, K.S., and S. Schäfer. Observed effects of a geomagnetic storm on an RTK positioning network at high latitudes. J. Space Weather Space Clim., 2, A13, 2012, DOI: 10.1051/swsc/2012013.

Jakowski, N., S. Heise, A. Wehrenpfennig, and K. Tsybulya. Ionospheric Radio Occultation Measurements and Space Weather. In: G. Kirchengast, U. Foelsche, A.K Steiner, Editors, Occultations for Probing Atmosphere and Climate, Springer Berlin Heidelberg, 383-392, 2004,

DOI: 10.1007/978-3-662-09041-1_34.

Jakowski, N., C. Mayer, C. Borries, and V. Wilken. Space weather monitoring by ground and space based GNSS measurements, Proc. ION - International Technical Meeting, January 26-28 Anaheim, CA2009.

Jakowski, N., C. Mayer, M.M. Hoque, and V. Wilken. Total electron content models and their use in ionosphere monitoring. Radio Sci., 46, RS0D18, 2011, DOI: 10.1029/2010RS004620.

Koutroumbas, K., I. Tsagouri, and A. Belehaki. Time series autoregression technique implemented on-line in DIAS system for ionospheric forecast over Europe. Ann. Geophys., 26 (2), 371-386, 2008

Kutiev, I., and P. Marinov. Topside sounder model of scale height and transition height characteristics of the ionosphere. Adv. Space Res., 39, 759-766, 2007.

Kutiev, I., P. Marinov, and S. Watanabe. Model of the topside ionosphere scale height based on topside sounder data. $A d v$. Space Res., 37 (5), 943-950, 2006.

Kutiev, I., P. Marinov, A. Belehaki, B. Reinisch, and N. Jakowski. Reconstruction of topside density profile by using the Topside Sounder Model Profiler and Digisonde data. Adv. Space Res., 43, 1683-1687, 2009a

Kutiev, I., P. Marinov, A. Belehaki, N. Jakowski, B. Reinisch, C. Mayer, and I. Tsagouri. Plasmaspheric electron density reconstruction based on the Topside Sounder Model Profiler. Acta Geophys., 58, 420-431, 2009b.

Kutiev, I., P. Marinov, S. Fidanova, A. Belehaki, and I. Tsagouri. Adjustments of the TaD electron density reconstruction model with GNSS TEC parameters for operational application purposes. J. Space Weather Space Clim., 2, A21, 2012, DOI: $10.1051 / \mathrm{swsc} / 2012021$

Lilensten, J., and A. Belehaki. Developing the scientific basis for monitoring, modeling and predicting space weather. Acta Geophys., 57 (1), 1-14, 2009.

Lilensten, J., Lj.R. Cander, M.T. Rietveld, and P.S. Cannon. Comparison of EISCAT and ionosonde electron densities: application to a ground-based ionospheric segment of a space weather programme. Ann. Geophys., 23, 183-189, 2005. 
Marinov, P., I. Kutiev, A. Belehaki, and I. Tsagouri. Modeling the plasmasphere to topside ionosphere scale height ratio. J. Space Weather Space Clim., 5, in press, 2015, DOI: 10.1051/swsc/2015028.

McNamara, L.F., C.R. Baker, and D.T. Decker. Accuracy of USUGAIM specifications of foF2 and M(3000)F2 for a worldwide distribution of ionosonde locations. Radio Sci., 43, RS1011, 2008, DOI: $10.1029 / 2007$ RS003754.

Mikhailov, A.V., A. Belehaki, L. Perrone, B. Zolesi, and I. Tsagouri. On the possible use of radio occultation middle latitude electron density profiles to retrieve thermospheric parameters. J. Space Weather Space Clim., 4, A12, 2014, DOI: 10.1051/swsc/2014009.

Radicella, S., and B. Nava. NeQuick model: Origin and evolution, in Antennas Propagation and EM Theory (ISAPE), in 2010 9th International Symposium, Guangzhou, 422-425, 2010.

Reinisch, B.W., and I.A. Galkin. Global ionospheric radio observatory (GIRO). Earth, Planets, and Space, 63, 377-381, 2011, DOI: 10.5047/eps.2011.03.001.

Rietveld, M.T., B. Isham, and I. Häggström. Calibration of EISCAT incoherent scatter radar electron densities and the anomaly of 2325 October 2003. EISCAT (European Incoherent Scatter) Scientific Association Report, v. 20071114, 2005.

Tsagouri, I. Evaluation of the performance of DIAS ionospheric forecasting models. J. Space Weather Space Clim., 1 (1), A02, 2011, DOI: $10.1051 / \mathrm{swsc} / 2011110003$

Tsagouri, I., and A. Belehaki. An upgrade of the solar-wind-driven empirical model for the middle latitude ionospheric storm-time response. J. Atmos. Sol. Terr. Phys., 70, 2061-2076, 2008, DOI: $10.1016 /$ j.jastp.2008.09.010.

Tsagouri, I., and A. Belehaki. Ionospheric forecasts for the European region for space weather applications. J. Space Weather Space Clim., 5, A09, 2015, DOI: 10.1051/swsc/2015010.
Tsagouri, I., B. Zolesi, A. Belehaki, and Lj.R. Cander. Evaluation of the performance of the real-time updated Simplified Ionospheric Regional Model for the European area. J. Atmos. Sol-Terr. Phys., 67 (12), 1137-1146, 2005

Tsagouri, I., K. Koutroumbas, and A. Belehaki. Ionospheric foF2 forecast over Europe based on an autoregressive modeling technique driven by solar wind parameters. Radio Sci., 44, RS0A35, 2009, DOI: 10.1029/2008RS004112.

Yue, X., W.S. Schreiner, and Y.-H. Kuo. A feasibility study of the radio occultation electron density retrieval aided by a global ionospheric data assimilation model. J. Geophys. Res., 117, A08301, 2012, DOI: 10.1029/2011JA017446.

Zolesi, B., and Lj.R., Cander. Advances in regional ionospheric mapping over Europe. Ann. Geofis., 41 (5-6), 827-842, 1998.

Zolesi, B., and Lj.R. Cander. Effects of the upper atmosphere on terrestrial and Earth-space communications: final results of the EU COST 271 Action. Adv. Space Res., 37, 1223-1228, 2006.

Zolesi, B., and Lj.R. Cander. From COST 238 to COST 296: four European COST Actions on Ionospheric Physics, Radio Propagation, in Radio Sounding and Plasma Physics Symposium, April 29, 2007, XI International Digisonde Forum, April 30 May 3, 2007, American Institute of Physics, AIP Conference Proceedings, volume 974, 39-46, 2008.

Zolesi, B., Lj.R. Cander, and G. de Franceschi. Simplified Ionospheric Regional Model for telecommunication applications. Radio Sci., 28 (4), 603-612, 1993.

Zolesi, B., A. Belehaki, I. Tsagouri, and Lj.R. Cander. Real-time updating of the Simplified Ionospheric Regional Model for operational applications. Radio Sci., 39 (2), RS2011, 2004, DOI: $10.1029 / 2003 \mathrm{RS} 002936$

Cite this article as: Belehaki A, Tsagouri I, Kutiev I, Marinov P, Zolesi B, et al. The European Ionosonde Service: nowcasting and forecasting ionospheric conditions over Europe for the ESA Space Situational Awareness services. J. Space Weather Space Clim., 5, A25, 2015, DOI: $10.1051 /$ swsc/2015026. 